\title{
Particulate Solid Attrition in CFB Systems - An Assessment for Emerging Technologies
}

Samuel C. Bayham ${ }^{1,2}$, Ronald Breault ${ }^{1, *}$, Esmail Monazam ${ }^{1,3}$

${ }^{1}$ National Energy Technology Laboratory; 3610 Collins Ferry Road, Morgantown, WV, USA 26507

2 Oak Ridge Institute for Science and Education

${ }^{3}$ REM Engineering Services; 3537 Collins Ferry Road, Morgantown, WV, USA 26505

${ }^{*}$ Corresponding author: T: 304-285-4486 E: ronald.breault@netl.doe.gov

\section{Abstract}

Over the years, circulating fluidized bed systems have been designed for chemical conversion and energy recovery due to the ability of allowing continuous processing. While many CFB technologies are well established, a number of emerging technologies in recent years are utilizing the CFB concept, such as chemical looping combustion, novel continuous temperature swing adsorption, and transport gasifiers. A major uncertainty in these new technologies is the effect that attrition of bed material has on the overall process economics and system operability. This work presents a review of the study of attrition for CFB systems, including relevant material properties, basic modeling and prediction, as well as particle population balance techniques. Because some of these new processes use novel materials, this work focuses on applying fundamental material properties to the understanding of attrition. 


\section{Graphical Abstract}

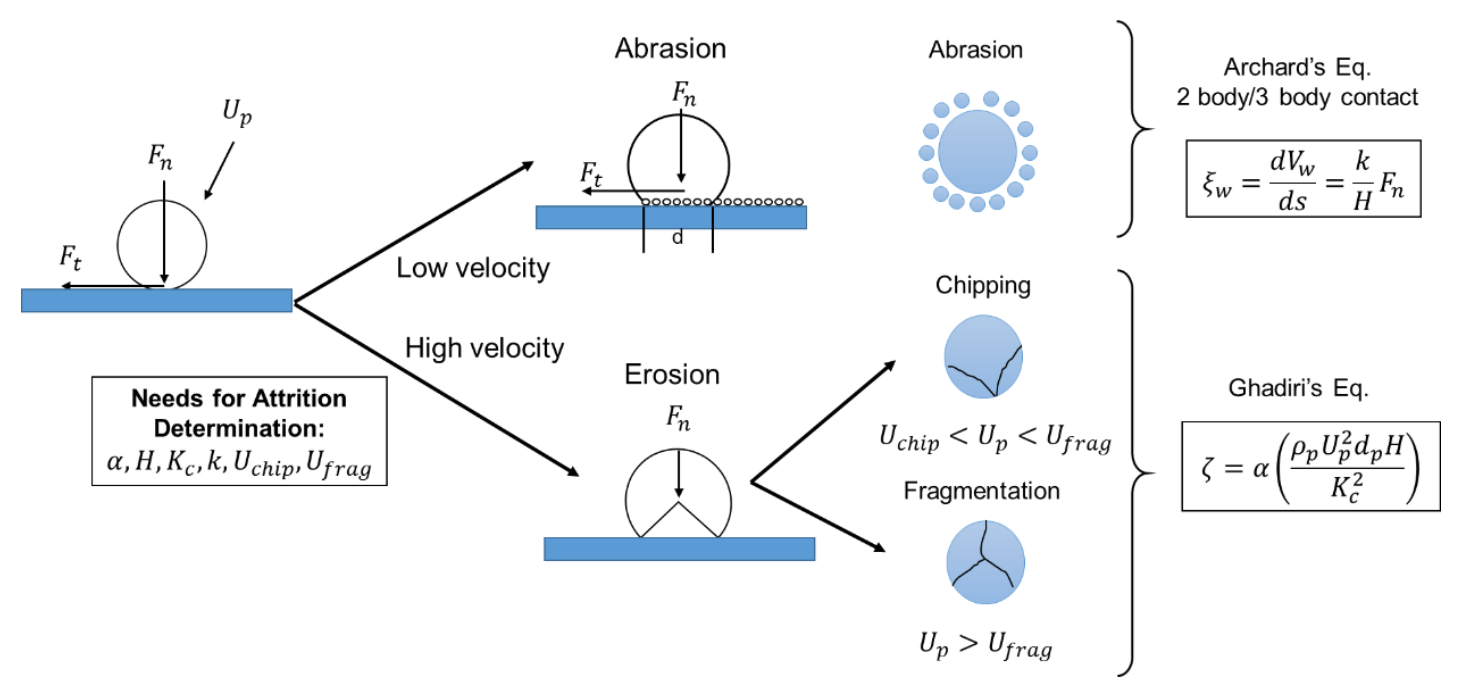

\section{Introduction}

A circulating fluidized bed system (CFB) consists of a fluidized bed that operates with a high entrainment flux of solids, with separation of the solid material from the carrying gas, and subsequent reintroduction of the solids back into the fluidized bed [1]. The CFB configuration is a staple of process industry, being utilized in catalytic cracking of petroleum, fluidized bed combustion, ore roasting, gasification, etc. [2]. The concept of the CFB system provides numerous advantages to processes, including the ability for continuous operation, good mixing, contact, heat transfer, and controllability of residence times [1]. For many of these reasons, in addition to the maturity of the concept and the aforementioned technologies, the CFB concept is also being utilized in the design of newer, advanced technologies. A list 
of these technologies include chemical looping combustion [3], solar power plants [4], circulation of TSA sorbents for $\mathrm{CO}_{2}$ capture [5], and advanced gasification and coal-to-liquids configurations [6].

While the advantages of CFB systems are many, a significant disadvantage is the potential for attrition due to the high gas and solid velocities in the process. Particle attrition is defined as the breakdown of solids in a system whose main design intent is not comminution [7]. Among various reasons why attrition is undesirable in a CFB system, the greatest reason for novel energy systems that use a tailored catalyst or sorbent is the cost required to replace the attrited material. For novel, emerging processes, this has the potential to offset the economic benefits that the emerging technologies are trying to attain. For example, chemical looping combustion (CLC) is an advanced oxy-combustion technology that produces a concentrated sequestration-ready $\mathrm{CO}_{2}$ stream in power production in two stages, potentially reducing the cost of $\mathrm{CO}_{2}$ capture significantly compared to first-generation technologies. The CLC concept has the advantage that the oxygen needed for fuel combustion is supplied by means of a cyclically-reacted oxygen carrier instead of being taken directly from air. The oxygen-carrier is usually circulated between two fluidized beds, one in which the fuel is oxidized by the carrier, the other in which the carrier is re-oxidized by air. As a results, the particles are subjected to high mechanical stresses caused by interparticle collision and bed to wall impacts, thereby resulting in particle attrition. It is also well known that both thermal stresses and chemical reaction can have an effect on the propensity of a particle to undergo attrition. Therefore particle attrition is a major issue that can cause many problems such as inventory losses which impact significantly the operating costs. Thus, the choice of the oxygen carrier particles is a key parameter for the process development of CLC to allow for minimization of cost.

Due to the serious implications that attrition potentially has on process economics and system operability, attrition has been studied in industry extensively at laboratory scale for many years using a variety of apparatuses. A list of these apparatuses includes the Davidson 
jet cup [8], the three-orifice fluidized bed, also known as ASTM 5757 [9], force gages that measure single particle crushing strength, and others. Despite their widespread use and inclusion as standard methods of attrition testing, these apparatuses are able to only qualitatively or, at best, semi-quantitatively determine the extent of attrition, and most of these tests require comparison to a benchmark sample. For example, Ryden et al. found little correlation between the single particle crushing strength and the attrition results from their testing [10]. The tests are at best able to screen solid materials as well as provide relative comparisons and comparisons to benchmark materials, but determination of an absolute quantitative mass loss or makeup rate, and corresponding operational cost of makeup material, is impossible.

On the other hand, basic predictive models based on surface energy have been developed for various unit operations in a CFB system. Examples of predictive attrition models include that for cyclones [11], the upper bubbling zone [12] and the jet grid zone [13] of a densephase fluidized bed. These cited models are derived based on an energy balance; the kinetic energy added by the gas or due to the motion of the particle is translated to the formation of new surface, based on an assumed efficiency. Given system parameters, such as the gas velocity, jet orifice size, solids loading, etc., the attrition rate can be calculated if the constant is known. While in many of these models the constant is based on the surface free energy, which is a material parameter, the attrition constants are in practice measured from smallscale experiments in the respective unit operations due to the unknown efficiency terms found in the constant. Thus, it is difficult to ascertain the makeup rate, and subsequently the makeup cost, from these models a priori since they are not based on fundamental material parameters.

In order to better understand the attrition phenomena experienced by carriers in CLC systems, this work will study the extent and causes of carrier attrition due to surface abrasion, particle impaction, and thermal effects. As opposed to other reviews on attrition, this work will 
also place a stronger emphasis on fundamental material properties or parameters important to predicting attrition and catalyst performance. Most of this work will also focus on newer research, usually published after 1990 or so. Many great reviews have been written for work before this time $[14,15]$, which provide greater emphasis on the experimental apparatuses. It should be noted that the scope of this work will be on attrition, where material degradation is unintentional and an economic detriment to the process, as opposed to comminution, where degradation is the end goal, e.g., in a coal pulverizer or ball mill. However, helpful aspects from comminution research, such as Kick's and Rittinger's laws, can be applied to aid in interpretation of attrition data, as knowledge of the energy applied to the material in question, regardless of its source (e.g., gas jet or ball mill) should follow the same laws.

This work is divided into several sections. First, an overview of the sources and mechanisms of attrition will be discussed. These are broken down into mechanical, thermal, and chemical stresses, which are exhibited in the different unit operations of a CFB system, such as fluid beds, cyclones, risers, etc. Next, important material properties relevant to attrition will be discussed, along the lines of strength of materials. The discussion will continue with a summary and analysis of the mathematical expressions derived or experimentally determined for attrition in corresponding unit operations in a CFB system. Population balance models will also be discussed, which help to tie together the concepts of attrition and particle size distribution. The work will end with an assessment of the present state of predictive abilities for attrition.

\section{Sources of attrition in CFB systems}

Because of the weak nature of catalysts and the existence of a great variety of forces and energy sources in a CFB, attrition in such systems is multifaceted and ubiquitous. Various authors have defined the term attrition slightly differently. For the purposes of this paper, attrition 
will be defined as the unintentional breakdown of the solid material, either catalyst, sorbent, or "oxygen carrier", which is the term used for the particulate solid used in chemical looping combustion. Figure 1 shows that attrition can be divided into two main types: abrasion and fragmentation [15]. When particles are subject to low velocity collisions, the main mechanism of attrition is by surface abrasion. This consists of the wearing of surface asperities, leading to the production of very fine particles, which are easily elutriated. Given mother particles of a single normal particle size distribution, abrasion results in the formation of a bimodal particle size distribution. At higher velocity, attrition is controlled by particle fragmentation in which the particles breaks into two or more fragments that are non-elutriable and then subject to further attrition. Fragmentation is also broken down into primary fragmentation, which for example is the result of feeding fresh particle into a hot furnace, and secondary fragmentation, which is fragmentation that occurs in the fluid bed or in the process [10]. In summary, abrasion is generally more responsible for fines production and economic losses from material elutriation and replacement of the lost sorbent, while fragmentation causes greater changes in the mean bed particle size, resulting in decreased performance and increased control issues [16]. The production of particle fragments however allows for the possibility of a greater rate of surface abrasion, since the daughter particles from fracture are non-spherical, and the protuberances are more easily worn compared to spherical particles.

Attrition of particles can be expected when the material undergoes stress in any of the three categories: (1) thermal, (2) chemical, and (3) mechanical (or hydrodynamic) [12,17]. These are described in detail as follows.

Thermal stress is produced as a result of the uneven expansion or contraction of the particle as it is heated or cooled, causing decrepitation [18]. When cold particles are added to a high-temperature region, such as that introduced into a hot fluidized bed, the material can spall due to thermal shock [12]. Examples of this include the addition of cold solid fuel to a hot fluidized bed combustor or 
the addition of cold makeup catalyst or sorbent to the system. Additionally, the thermal stress is exacerbated when the particles are spatially confined, e.g., at the bottom of a standpipe or bed, and when the particles undergo cyclic heating and cooling, e.g., in a chemical looping system, where the particles undergo reduction at one temperature and oxidation at a higher temperature.

Chemical stress is produced as a result of chemical reaction on the surface of the particle (e.g., fluidized catalytic cracking or $\mathrm{CO}_{2}$ adsorption catalysts) or within the particle (e.g., coal or metal oxide oxygen carrier). Chemical reaction produces internal stresses that change the lattice structure, which weakens the particles and produces surface features that can be easily abraded upon application of small external stresses. For solids that undergo chemical reaction in CFB systems, the phase change of the parent material produces different physical properties due to each possible phase in the particle consisting of different properties. For example, for the reduction of hematite by carbon monoxide or hydrogen, such as in a chemical looping system, the hardness of the material was shown to decrease due to the reduction in hardness of the corresponding phases [19]. Additionally, if the surface reaction is highly exothermic, chemical stress can be coupled with thermal stress, causing temperature gradients to occur. This can occur for example when coked catalyst becomes regenerated by combustion with air.

Mechanical stresses are those that are a result of compression, tensile, or shear stresses on particulate material, which can be the result of the simple support of static loads or more complex due to the dynamic motion of particles. Thus, the designation is divided into two areas: static and kinetic [18]. Static stress can be the result of particles undergoing a compressive load with no motion or a very low-velocity movement of solids, such as in the lower portion of a standpipe, at the bottom of a bed, or in a silo. Kinetic mechanical stresses involve the motion of solids, whether at high velocity such as impacts with the wall in a riser, or at lower velocity, where the particles rub together when bubbles pass through a fluidized bed. The particles can undergo both compressive and tensile stresses. When particles undergo 
impact, tensile stresses are exhibited as a portion of the material wedges the particle apart; after a low or high-velocity impact, the particle can crack under the release of residual tensile stresses [20, 21].

A summary of the locations in a CFB where attrition due to mechanical (static and kinetic) stress is likely to occur are shown in Figure 2. The locations for attrition to occur consist of (1) fluidized bed, (2) conveying lines and risers, (3) cyclones or other gas-particle separation devices, (4) hoppers and standpipes, and (5) rotating seals or screw feeders [7].

The sources of attrition in a fluidized bed are threefold. The first area is bubble attrition (1a in Figure 2), which is the result of particles rubbing against each other due to bubbles passing through the bed [22]. Thus, the main mechanism of this type of attrition is particleparticle abrasion. The attrition rate is proportional to the "excess" velocity in the bed, namely the superficial gas velocity minus the minimum fluidization velocity, as will be described later. Second, in beds that do not use porous distributor plates, or in beds where the introduction of fluidizing gas is highly localized, grid jet attrition can occur (1b in Figure 2). The jets have the propensity to provide a high amount of kinetic energy to the solids by circulating solids locally through the bottom of the jet and accelerating particles towards other particles. Thus, gas jets provide a location for both abrasion and erosion, since the impact can produce fragmentation or chipping due to the high impact velocity. The third area is the freeboard region (1c in Figure 2), where breakage of bubbles causes whole particles to become ejected into the freeboard region to impact other particles or the wall. This area is more difficult to quantify, but since it consists of a small region of low-velocity impacts, the attrition due to this cause can be preliminarily assumed to be negligible, except for fluidized beds in the turbulent fluidization regime. Depending on the conditions, the freeboard attrition can also be assumed to be negligible if the particle-particle impact velocities are lower than the threshold velocities required to initiate chipping and/or fracturing. 
For risers and conveying lines, the gas velocity required to convey particles has the potential to create high-velocity impacts for particles near sharp turns or bends [23]. Additionally, in some CFB designs, the particles may impact U-beams which intend to separate flue gas from the bed material [24] and anti-wear beams in the riser that intend to reduce the downward particle velocity in the annular region $[25,26]$. Impact in these locations can cause significant particle fragmentation if the impact velocity is above the threshold velocity.

Because the principal of operation of a cyclone requires high velocities of gas and solid flow to separate gas and solids, the rate of attrition has the potential to be high. Zenz has stated that attrition in cyclones for an FCC process has shown to be several orders of magnitude greater than gas grids in the fluidized bed [27]. For a traditional reverse-flow cyclone, there are two main regions where particle attrition occurs. The first area is a result of high-velocity impacts of the particles at the tangential inlet section of the cyclone. The incoming particles are thrusted towards the wall due to the vortex pressure gradient [11]. This mode is mainly prevalent for fresh catalyst materials, where the weaker fraction of the manufactured material is easily fractured as a result of impact, producing daughter particles that are easily worn down. As the system attrition reaches a steady state, the mode mainly shifts to particle abrasion, which is the result of particles sliding against the walls of the cyclone as they travel down towards the collection hopper or standpipe [7,28]. Thus, the primary modes of attrition in a cyclone are both due to both erosion and abrasion, depending on whether the attrition has reached a steady state. For steady state abrasion, the rate of attrition has been shown to be a function of the inlet gas velocity to the power of 2.5 [11]. Surprisingly, the rate of steady-state attrition in cyclone experiments has been shown to be independent of cyclone geometry [11].

Other sources of mechanical attrition in CFB systems include standpipes and hoppers. The main mode of attrition is by abrasion of particles with the wall of the standpipe and additionally by particle-particle abrasion due to radial solid velocity gradients. Additionally, for standpipes that have gas injected locally, such as non-mechanical valves, the attrition can be a result of fragmentation, similar to that 
for jets as described for fluidized beds. However, in population balance models used for determining particle size distribution as a function of time and attrition in CFBs, the abrasion in the standpipe has been assumed to be negligible [28].

In terms of particle size, the larger the particle, the easier it should be to cause the particle to attrit or comminute, viz. larger particles require less energy per unit mass to break down. This can be attributed to the fact that many solids contain a natural grain size. Assuming that the particle will tend to undergo transgranular fractures (i.e., the weak defects within the crystalline grains are stronger than the intergranular bonds), attrition of the particle will cause the material to break down to the individual grains [30]. This can be described phenomenologically by the crushing laws of Kick, Rittinger, and Bond, which states that the incremental energy increase required to break an incrementally larger particle is inversely proportional to the particle size.

$$
\frac{d E}{d d_{p}}=-\frac{k}{d_{p}^{n}}
$$

The exponent for the particle size term is $n=1$ for Kick's law, $n=3 / 2$ for Bond's law, and $n=2$ for Rittinger's law [31]. Thus, as can be seen from this equation, the energy required to go from an initial particle size down to a smaller one increases.

\section{Properties of solids relevant to attrition}

As described previously, the attrition of particulate solids can be divided into abrasion (wear) or erosion (fragmentation). This section will delve deeper into these topics to show how to quantify the rate of each process based on known material properties. In theory, with knowledge of the phenomenological rate laws for a material, the rate of attrition can be determined using information about the stresses 
and strains exhibited in various sections of a CFB system. Many of these parameters described in the proceeding sections are summarized in Figure 3.

\section{$\underline{3.1 \text { Hardness }}$}

Hardness is defined as the resistance to local plastic deformation on a material's surface. Historically, hardness has been categorized into three different types: (1) scratch, (2) static indentation, and (3) dynamic or rebound hardness [32]. Scratch hardness describes the ability of standard materials to scratch a sample, and its use is limited to simple characterization in mineralogy. Indentation hardness of a material is quantified by applying a load to an indenter of a certain shape and measuring the resulting area of indentation. Examples of such tests include that by Brinell, Vickers, Knoop, and Rockwell [33]. The hardness value mainly used for attrition research is the indentation hardness, and this parameter shows up in numerous models for abrasion and erosion, both for particulate and nonparticulate (e.g., agglomerate) materials [34]. For a Vickers pyramid, dividing the load applied by the area of indentation formed, based on the length of the indents from the pyramid, the hardness is obtained with a unit of pressure. Hence, the Vickers hardness, $H$, is then determined from a relationships between the load and the depth of penetration [35].

$$
H=1.8544 \frac{F}{l^{2}}
$$

where $F$ is the contact force and $l$ is indentation length. 
As described in later sections, the hardness of a material is an important parameter for determining the rate of wear and the loss of material upon impact. For applications of wear, assuming that the hardness of the asperities are the same as the entire material, asperities are broken off when the load applied is close to the flow pressure, which is related to the hardness [36].

There are a number of factors that affect the hardness of a material, and hence the rate of attrition (both abrasion and erosion). The surface treatment of particles, such as in a fluidized bed or in a ball mill [37], causes the particles to become work hardened [38]. Work (or strain, or cold) hardening is the resulting increase of surface hardness due to the application of loads that cause plastic deformation. The hardening of the surface is a result of the increase in dislocations in the material [33]. Since the dislocations exhibit localized fields of compression and tension, and since the number of dislocations increase with strain, the motion of the dislocations is constrained due to repelling of the compression or tension fields [33]. This is usually reversed by applying heat to the material, which releases the stress around the dislocations. Kimura et al. studied the effects of ball milling on the microhardness of iron powder (-100 mesh), and the Vickers hardness increased from around $50 \mathrm{HV}(\sim 0.5 \mathrm{GPa})$ up to $950 \mathrm{HV}(\sim 9.5 \mathrm{GPa})$ due to the work hardening effect [37]. Ghadiri et al. indicate that work hardening of sodium chloride crystals occurred for samples that were dried in a fluidized bed and centrifuged as opposed to rotary vacuum filtered and dried [38].

Another important factor for hardness is the temperature, which can change the hardness in two ways. The first effect is due to the existence of different phases of the material at different temperatures, since different phases can have different hardness. The existence of different phases is also attributed to the partial pressure of the oxidizing or reducing gases in the particle environment. The second effect is, for a specific phase of the material, due to the temperature effect itself. Generally, the hardness of a material decreases with temperature due to overcoming dislocation strains by the added thermal energy. Takeda et al. showed the effects of temperature, from 
room temperature to $1000^{\circ} \mathrm{C}$, on iron oxides and an iron silicate; the Vickers hardness (HV) is shown in Figure 4 [39]. As shown, the hardness of the oxides decrease with increase in temperature, and the magnitude of decrease occurs in the following order: $\mathrm{Fe}_{2} \mathrm{SiO}_{4}, \mathrm{Fe}_{2} \mathrm{O}_{3}$, $\mathrm{Fe}_{3} \mathrm{O}_{4}$, and $\mathrm{FeO}$. Furthermore, the hardness of $\mathrm{Fe}_{2} \mathrm{SiO}_{4}$ and $\mathrm{Fe}_{2} \mathrm{O}_{3}$ are especially high at room temperature, but above $400^{\circ} \mathrm{C}$, the hardness of the two are similar to the lower oxidation states. Among the components, the lowest oxidation state is the softest material. From this analysis, it should be noted that iron oxide, as indicated, is a proposed oxygen carrier for chemical looping combustion, so as the hardness decreases with increase in temperature, the rate of wear will increase due to the softening of the material, ignoring other factors such as work hardening. Additionally, ignoring the chemical stress introduced by chemical reaction, as the oxygen carrier becomes reduced in the fuel reactor, the oxygen carrier drops to a lower oxidation state, which is also a softer material. Thus, these parameters need to be taken into effect the attrition models for particulate solids.

\section{$\underline{3.2 \text { Fracture toughness }}$}

While with the naked eye it may seem that a material is smooth and without imperfection, the material usually contains microscopic flaws such as gaps, cracks, or fissures. When an external load is applied to the material, the gaps in the material act as "stress raisers", or "stress concentrators", causing the stress at the tips of these cracks to go beyond the yield stress—or even the ultimate stress—of the material, even if the external stress applied is not above the yield stress. Depending on the curvature of the crack at the tip, the effective stress at the tip can be as high as 4-60 times the stress applied externally to the material [40]. The microscopic gaps in material explain why, for brittle materials, the actual ultimate stress of materials is much lower than the theoretical stress derived from knowledge of the cohesive forces and bond strength for a perfect material, which in terms of order of magnitude is usually one tenth of the Young's modulus [33]. 
In general, the state of stress around a crack in a material can be determined with knowledge of the crack size and load applied. The critical combination of applied external stress to a material and the crack size is a material parameter that is called the critical stress intensity factor, or sometimes the fracture toughness [41]. Fracture toughness can be thought of as the resistance to brittle fracture, whereby a high value of the fracture toughness will indicate that failure is more likely to occur through ductile fracture. It is also an indication of the propensity for crack propagation, given a crack size and applied load.

While the critical stress intensity factor is defined for tensile stresses applied to cracks, the concept still applies to particles undergoing compressive stresses externally. Analysis by Griffith has shown that a crack with an orientation parallel to the external applied (uniaxial) compressive stress has tensile stresses at ninety degree angles from the tips of the cracks; furthermore, the maximum tensile stresses are seen with crack orientation at 30 degrees from the externally applied compressive stress [7]. Additionally, below a certain particle size, the size of flaws in the material becomes insufficient to cause brittle fracture and will plastically deform, even if highly brittle [20].

The critical stress intensity factor for a material is a function of a number of parameters. The temperature plays a role in the degree of ductility the material exhibits: the higher the ductility, the more likely the material will undergo ductile fracture instead of brittle fracture. This is shown qualitatively in Figure 5. Tensile tests are performed on different oxidation states of iron oxide at various temperatures, ranging up to $1250^{\circ} \mathrm{C}$ in the work of Hidaka et al. [42]. For alpha- $\mathrm{Fe}_{2} \mathrm{O}_{3}$, the fracture of the specimen is via brittle fracture at $800^{\circ} \mathrm{C}$, via intergranular fracture at $1000^{\circ} \mathrm{C}$, and via ductile fracture indicated by necking at $1200^{\circ} \mathrm{C}$ [42]. The fracture toughness is a strong function of the temperature and microstructural properties (e.g., grain size) of the material [33]. Iron oxide is a proposed material for chemical looping combustion processes, so for example, at higher temperatures, the material will have a higher fracture toughness and, ignoring 
factors such as chemical stress, will be more likely to withstand higher-velocity impacts. However, temperature effects on the fracture toughness of a material are complex, so a detailed study of the fracture mechanisms is needed for the material in question.

The composition has a strong influence on the crack toughness, as it describes the propensity to produce plastic deformations around the crack tip. Rocha-Rangel studied the effect of metallic additions to aluminum oxide that formed composites on the indentation fracture toughness, the results which are graphically shown in Figure 6 [43]. Naturally, aluminum oxide is a ceramic material, being brittle yet strong, and its fracture toughness is the lowest value as shown in Figure 6. Aluminum metal is ductile, so its addition to alumina is more likely to form ductile fractures, and its fracture toughness is greater than its oxidized form. Furthermore, adding other ductile metals such as nickel and titanium to the aluminum matrix caused an increase in fracture toughness. The added metals are able to bridge the cracks, causing closing stresses [43]. Additionally, certain elements also help to maintain a homogeneous microstructure in the material. In the study of the mineral grains in rocks, measurements by Viktorov et al. show that magnetite $\left(\mathrm{Fe}_{3} \mathrm{O}_{4}\right)$ has a greater fracture toughness than hematite $\left(\mathrm{Fe}_{2} \mathrm{O}_{3}\right)$, which is due to the lower oxidation state being more ductile [44].

\subsection{Attrition due to wear}

The rate of wear (abrasion) can be deduced from laws in the area of tribology, which is the study of rubbing or sliding of solid surfaces [34]. While the study of wear is not new, a universal model for abrasion between two surfaces based on material properties, loads, and sliding distances is not available; rather, there exist hundreds of models that describe the rate of wear based on parameters such as applied load, material properties, and sliding distance [45]. The wear models in the literature can be categorized as (1) empirical, (2) contact-mechanics based, and (3) material failure mechanism [45]. A contact-mechanics based model that has found moderate success is 
derived from Archard [46] which argues that the distance rate of wear (the volume worn per distance traveled) of surface asperities is independent of the actual contact surface area and linearly dependent upon the normal load applied $(P)$ between the two surfaces and inversely proportional to the material hardness $(H)[46]$ :

$$
\xi_{w}=\frac{d V_{w}}{d s}=\frac{k}{H} P
$$

where $k$ is a wear constant, which is added to account for the fact that not all asperity contacts result in breakage. Typically for two-body cases, $k$ is in the range of $0.006<k<0.06$ and for 3-body cases, it is in the range $0.0003<k<0.003$ [36]. The abrasion of particulate solids could be considered a multi-body problem, depending on the conditions. Thus, for a material with a known hardness and wear characteristics, if the normal load is known as well as the distance traveled, the wear volume can be calculated.

An important factor to consider in wear experiments that utilize Archard's law is the effect of the initial unsteady-state "break-in" wearing period that is exhibited for fresh materials. For non-particulate samples in tribology experiments, it has been shown that this unsteady period at the start of the experiment is due to wearing down of very rough asperities, as shown in Figure 7 as a plot of the wear volume or the standard wear coefficient versus sliding distance. After the initial startup period, the wear coefficient approaches an asymptote and can describe the degree of wear in a system at steady-state [47]. This is different than the "cushioning effect" found in comminution experiments in linear time-variant population balance models [48]. 
Wear has also been considered due to the formation of subsurface lateral cracks due to a chipping mechanism. Ning and Ghadiri propose the following relation for wear based on a material failure mechanism due to a particle sliding a curved distance $L$ over another particle [49]:

$$
V_{w}=\frac{0.07 P^{\frac{5}{4}}}{\pi^{\frac{5}{4}} K_{c} H^{\frac{1}{4}}}\left(2 L+\frac{\pi^{\frac{1}{4}} H^{\frac{1}{4}} P^{\frac{3}{4}}}{17.1 K_{c}}\right)
$$

Where $P$ is the load applied, $K_{c}$ is the fracture toughness, and $H$ is the material hardness (assumed the same for both particles). The equation for wear is based on a material relation between the crack length and the indentation radius [49], the contact radius can be related to the hardness and load applied (similar to Archard's law), and that both surfaces undergo wear (which is an overestimate, according to Ning and Ghadiri).

\subsection{Impact attrition}

A mechanistic model to describe the fragmentation or chipping process was also developed by Ghadiri and Zhang [21]. The formulation of the model is based on the indentation fracture mechanic of lateral cracks. A fractional loss per impact, $\zeta$, is define as the ratio of the volume remove from a particle to the volume of the original particle. According to the model, the fractional loss per impact is given by

$$
\zeta=\alpha \frac{\rho_{p} U_{p}^{2} d_{p} H}{K_{c}^{2}}
$$


where $\alpha$ is a proportionality factor, $\rho_{p}$ is the particle density, up is the impact velocity, $d_{p}$ is a characteristic particle size, $H$ is the material hardness and $K_{c}$ is the critical stress intensity factor [21]. Gahn proposes a slightly different fractional volume removal model upon impact which is in the following form [50,51]:

$$
\zeta=\alpha \frac{\rho_{p} U_{p}^{\frac{8}{3}} d_{p} H^{\frac{2}{3}}}{G \beta_{\max }}
$$

Where $\mathrm{G}$ is the shear modulus of the material, and $\beta_{\max }$ is the maximum fracture energy of the material. Vogel and Peukert developed a different correlation based on Weibull statistics and parameters from dimensional analysis of Rumph [20] on comminution [52]. It relates the breakage probability to two "material" parameters $f_{m a t}$, which is a propensity of breakage parameter, and $W_{m, m i n}$, which is the minimum energy per unit mass required to cause breakage.

$$
S=1-\exp \left(-f_{\text {mat }} d_{p} f_{\text {coll }}\left(W_{m, k i n}-W_{m, \min }\right)\right)
$$

Where $d_{p}$ is the particle size, $f_{\text {coll }}$ is the frequency of impacts, and $W_{m, k i n}$ is equal to the mass-specific kinetic energy of impact $\left(W_{\text {m,kin }}=\frac{1}{2} U_{\text {impact }}^{2}\right)$. The parameter $f_{\text {mat }}$ is based on the crack extension energy and parameters related to the deformation (Young's modulus and Poisson ratio), but the material parameters are usually derived from data fitting of post-mortem particle size in controlled impact experiments. The equation is fit from data with the particle velocity upon impact as the abscissa, which is known, and the fraction of particles broken after impact. Further experiments were performed on a variety of pharmaceutical powders and show that the parameter $f_{\text {mat }}$ is proportional to the brittleness index, i.e., $H / K_{c}[51]$ : 


$$
f_{m a t} \propto \rho_{p}\left(\frac{H}{K_{c}}\right)^{2.5}
$$

Meanwhile, the minimum impact energy $W_{m, \min }$ was correlated to the property $f_{\text {mat }}$ in the following manner:

$$
d_{p} W_{m, \min }=\frac{C}{\rho_{p}}\left(\frac{f_{m a t}}{\rho_{p}}\right)^{-1.5}
$$

Where $C$ is a constant [51]. While this equation is intended for predicting comminution of materials, the equation could also be used for predicting attrition in risers, pneumatic conveying systems, etc., wherever high-velocity impacts could exist.

Other types of parameters have been developed that attempt to assess the extent of particulate breakage. Based on high-speed X-ray imaging of contacting brittle microspheres (600-2000 $\mu \mathrm{m})$ undergoing compression, Zbib et al. developed a comminution parameter that more accurately predicts the type of particulate failure mode undergoing compressive stress. The "pulverization parameter" is [53]:

$$
\mathcal{P}=\frac{H d_{p}}{K_{c} E^{5 / 3}}
$$

For low values of $\mathcal{P}$, compression of the particle results in a small number of large cracks, while large values of $\mathcal{P}$ produce many small cracks, i.e., shattering. The authors do not give specific threshold values, but the values indicate relative trends.

\section{Mathematical relations for attrition determination}

Over the years, numerous authors have attempted to develop expressions for estimating the extent of attrition. In terms of time, the rate of attrition can be broken down into two phases. The first phase is the unsteady state period where the attrition rate is high. This can be 
attributed to the rounding of sharp edges and protuberances on the particle in addition to the breakage of very weak particles. As time progresses, the second phase is reached, where the attrition rate decreases and reaches a steady state, occasionally described as approaching the characteristics of a Markov process [7,54]. From experience, this usually occurs when 3-5\% of the initial bed mass has been attritted [54]. Predictive steady state models for specific unit operations, such as jets in fluid beds, cyclones, etc., have been developed for the second phase. The two types of models are described separately below.

\section{$\underline{4.1 \text { Unsteady state models }}$}

The unsteady state period consists of an attrition rate that decreases steadily with time, usually in an exponential fashion. The most popular approach taken by researchers in deriving theoretical models for attrition processes has been through the application of a chemical kinetics analogy, whereby the rate of change of the weight of non-attrited solids in the bed is a function of the bed weight:

$$
\frac{d m}{d t}=f(m)
$$

Where $f(m)=-k m$ for a first order attrition process, with $k$ being an attrition constant. Paramanathan and Bridgwater reported that a simple first order kinetics model where the rate of disappearance of particles in a given size interval due to breakage is proportional to the weight of particles in an annular shear cell [55]. The model gives a limited agreement with experimental results. Along similar lines, Cook et al. performed attrition tests in a circulating fluidized bed, and after evaluating several different attrition models, the following second-order model was found to best fit their experimental data: 


$$
\frac{d m}{d t}=-k\left(m^{2}-m_{\min }^{2}\right)
$$

Where $m$ is the weight of the solids in the bed, $m_{\min }$ the minimum weight with which the attrition becomes negligible after long fluidization, and $k$ is the attrition rate constant.

The most successful and versatile model for describing attrition is the empirical formulation of Gwyn, who studied the relationship between attrition and time by measuring the production of sub-40 $\mu \mathrm{m}$ fines in a three-jet column [56]. Gwyn reported that the mass of fines produced is a non-linear function of time, in the form of a power-law

$$
\frac{m_{f}}{m_{0}}=k_{g} t^{b}
$$

Where $m_{f}$ is the mass of fines at time $t, m_{0}$ is the initial mass of bed material, $b$ is the power-law exponent, and $k_{g}$ is a constant. The constant is a function of the initial particle size through the following relation

$$
k_{g}=a d_{p 0}^{-\frac{2}{3}}
$$

Where $d_{p 0}$ is the initial particle size and $a$ is a constant. Thus, the diameter of a particle after a period of time $t$ is

$$
d_{p}(t)=\left(d_{p 0}-a t^{b} d_{p 0}^{-\frac{2}{3}}\right)^{\frac{1}{3}}
$$


Neil and Bridgwater found the formulation of Gwyn to describe their experimental data well for attrition of molecular sieve beads, heavy soda ash and tetra-acetyl-ethylene-diamine particles in various systems such as the annular shear cell, fluidized bed and screw pugmill $[57,58]$. Bridgwater also found it to be more satisfactory for describing attrition of high density polyethylene in an annular shear cell than a first-order kinetics model [59]. However, Bridgwater commented that Gwyn's formulation is incomplete in the sense that it implies an infinite initial attrition rate at zero shear strain and also allows the amount of attrited material to increase without bound at large strains. Ghadiri et al. [60] carried out annular shear cell experiments with porous silica catalyst beads and observed deviations of their experimental results from the Gwyn formulation under some operating conditions such as at high normal stress loads.

The rate constant for Gwyn model, the first-order model, and even the second-order model are generally derived from experimental studies, and it is difficult to determine the value a priori. However, Ayazi-Shamlou et al. attempted to apply aspects of hydrodynamic forces and the strength of particles (or agglomerates) to derive an expression for the rate constant [61]. Their work involved experiments on attrition of soda glass beads in a gas-fluidized bed and proposed a model which states that the rate of attrition is first order with respect to the total initial mass of intact particles and about 0.8 th order with respect to time. Their expression is loosely based on Gwyn's model and goes a step further to attempt to derive the rate constant based on an energy balance between energy input from the gas bubbles and the energy required to create new surface [61]. The kinetic constant is thus a ratio of these energies and includes an efficiency term. For bubble induced attrition (see also 4.2 Steady state expressions below), the energy added is

$$
\dot{E}_{b, e x}=m g\left(U-U_{m f}\right)
$$


Where $m$ is the mass of the bed. If the cohesive energy that holds the particle together is $f_{c}$, and the efficiency of energy transfer from the bubbles to the particles is $\eta$, then the rate constant can be defined as

$$
k_{g}=\eta \frac{m g\left(U-U_{m f}\right)}{f_{c}^{n}}
$$

Where $n$ is an exponent. Experimental evidence shows that the exponent for the surface strength is around 1.2-1.3 for particle agglomerates of known tensile strength [61, 62]. A similar expression can be defined for grid jet induced attrition [61].

Similar to the chemical kinetic analogy models described previously, Lim and Wang have developed a diffusion analogy for attrition, where the rate of attrition is proportional to the second spatial derivative of the solids concentration [63].

$$
\frac{\partial w}{\partial t}=D \frac{\partial^{2} w}{\partial x^{2}}
$$

Where $D$ can be interpreted as an "attrition diffusivity", analogous to the mass, thermal, or momentum diffusivities in transport phenomena. For a given system, the partial differential equation can be solved given distinct boundary and initial conditions. Lim and Wang have shown that their model fits reasonably well to the annular shear cell data of Paramanathan and Bridgwater [64] and Ghadiri et al. [60].

\subsection{Steady state expressions}

$\underline{4.2 .1 \text { Fluid bed }}$ 
As described previously, the attrition sources in a fluidized bed are a result of two areas: (1) grid jet gas impingement on the bed material and (2) rubbing of particles against each other and the wall due to bubbles passing through the bed material [7]. Because the phenomena are fairly different, the modeling for each is treated separately and assumed to follow the principle of superposition, i.e., the effects are roughly independent and additive.

The mechanism of jet induced attrition is due to impact of the particles with each other as well as abrasion of the solids that circulate around the jet [65]. Because of this, Ghadiri et al. have attempted to relate the jet-induced attrition rate to impact parameters [66]. On the other hand, Werther and Xi approach the steady-state jet attrition problem as if the material were pre-eroded, viz., the weaker particles are broken down in an initial phase. Similar to that for particle abrasion in a cyclone, their analysis assumes a certain efficiency in kinetic energy conversion of the jet gas $\left(\dot{E}_{i n}\right)$ to the energy required to abrade the bed material $\left(\dot{E}_{a b r}\right)$ :

$$
\eta_{j, a b r}=\frac{\dot{E}_{j, a b r}}{\dot{E}_{j, i n}}=\frac{\sigma_{p} S_{m i} R_{j, a b r}}{\frac{1}{2} \dot{m}_{o r} U_{o r}^{2}}
$$

Where $\sigma_{p}$ is the surface free energy (energy required to make new surface), $S_{m i}$ is the specific surface area of the abraded fines, $R_{j, a b r}$ is the rate of attrited fines production, $\dot{m}_{o r}$ is the mass flow rate of gas through one orifice, and $U_{o r}$ is the gas velocity through the orifice. The mass flow rate of gas is equal to

$$
\dot{m}_{o r}=\frac{\pi}{4} \rho d_{o r}^{2} U_{o r}
$$

Thus, the resulting attrition rate of fines due to jet abrasion is: 


$$
R_{j, a b r}=\left(\frac{\pi}{8} \frac{\eta_{j, a b r}}{\sigma_{p} S_{m i}}\right) \rho d_{o r}^{2} U_{o r}^{3}=C_{j e t} \rho d_{o r}^{2} U_{o r}^{3}
$$

Where $C_{j e t}$ is a material and efficiency constant [13].

For bubble-induced attrition, since the bubbles that form and break are the main cause of attrition, the rate is proportional to the excess gas velocity, viz., the superficial gas velocity minus the minimum fluidization velocity, since attrition due to mechanical motion does not occur if the bed is not fluidized [12]. Additionally, the mass of the bed $\left(m_{b e d}\right)$ is considered an important factor in the attrition rate.

The bubble-induced attrition can be derived once again from an energy balance approach between the input energy of the gas and the output energy of producing new surface. From extensive studies on limestone- and dolomite-based sorbents for fluidized bed combustion, Ulerich et al. [12] and Vaux and Keairns [18] developed a bubble-induced attrition correlation. The model is derived based on expressions that estimate the grams of fines produced during a collision, which is based on the velocity of collisions and the free surface energy of the solid material, and the number of collisions that occur per second, which is based on the bubble frequency. The relations use unknown proportionality constants to relate the bubble velocity to the particle collision velocity and the volume of fines produced to the unit of surface area generation. Additionally, it uses an efficiency term to relate the energy input from particle collision to the energy required to make new surface assuming a free surface energy term for the material. This results in the attrition rate, in the form of a modified Strouhal number, to the Bond number. The Strouhal number in this case is the ratio of attrition "frequency" to bubble frequency, where the excess gas velocity is proportional to bubble throughput, and the bond number is the ratio of gravitational force to surface forces, of the fluidized bed. 


$$
\frac{R_{b, a b r} h}{\left(U-U_{m f}\right)}=C\left(\frac{g \rho_{p} h^{2}}{\sigma_{p}}\right)
$$

With $R_{b, a b r}$ being the attrition rate, $h$ being the bed height, $U-U_{m f}$ being the excess gas velocity, $C$ being a bulk proportionally constant, and $\sigma_{p}$ being the particle free surface energy. Some iterations of the model contain as part of the constant the function $F(A)+1$, which describes the time dependence of the attrition rate, and $F(A)$ is around zero when the system is at steady state. It can be seen from the model that the particle size and the bubble size are not major parameters, since they cancel out in the derivation.

Along similar lines, Ray et al. describe bubble-induced attrition as an energy balance between the kinetic energy of the excess gas velocity $E_{k i n}$ in the bed and the energy that creates new surface $E_{\text {attr }}[30]:$

$$
\begin{gathered}
\dot{E}_{k i n}=m g\left(U-U_{m f}\right) \\
R_{b, a b r}=a \dot{E}_{a t t r}=a \eta \dot{E}_{k i n}=a \eta m g\left(U-U_{m f}\right)
\end{gathered}
$$

Where $a$ is an attrition constant, $\eta$ is the efficiency of energy transfer to the bed material. The efficiency may or may not be constant as a function of excess gas velocity, bed mass, or as a function of time. This equation is essentially similar to the equation by Ulerich et al., with the free surface energy tacitly included in the proportionality constant.

Thus, these ideas can be summarized as [22]:

$$
R_{b, a b r}=C_{b e d} m^{n}\left(U-U_{m f}\right)
$$


From experimental study, the exponent for the bed mass is usually between 1 and 2 [22]. Other important parameters that have been included in bubbling bed attrition models, whether erroneously or correctly, include the cross sectional area of the bed, the particle shape, particle size, etc. Based on these parameters, various researchers have proposed a number of expressions for bubble-induced attrition estimation.

For fluidized beds in general, the bubble-induced attrition and jet-induced attrition can be added together to achieve the total attrition rate. Based on dimensional analysis and experimental results, Zhang et al. propose the following expression for attrition in a fluid bed, both due to grid jets and bubbles [4]:

$$
R_{b, a t t r}=C_{1}\left(\Gamma\left(U-U_{m f}\right) \frac{m}{D}\right)+C_{2}\left(n_{o r} d_{o r}^{2} U_{o r}^{2}\right)
$$

Where $D$ is the diameter of the bed, $n_{o r}$ is the number of orifices in the bed, and $\Gamma$ is the bubble throughput, which is a function of the Archimedes number

$$
\begin{gathered}
\Gamma=2.27 A r^{-0.21} \\
A r=\frac{d_{p}^{3}\left(\rho_{p}-\rho\right) \rho g}{\mu^{2}}
\end{gathered}
$$

This model fit their data reasonably well within the range of conditions [4].

\subsubsection{Cyclone:}


A simple but useful steady state catalyst attrition model has been developed by Reppenhagen and Werther [11]. The model assumes a certain efficiency $(\eta)$ for transferring the kinetic energy of the particles, which is a function of the inlet gas velocity $U_{g a s, i n}$, to the creation of new catalyst surface by abrasion.

$$
\eta_{c}=\frac{\dot{E}_{c, a b r}}{\dot{E}_{c, i n}}=\frac{\dot{m}_{c, a b r} \sigma_{p} S_{m i}}{\frac{1}{2} \dot{m}_{\text {solids }, i n} U_{g a s, i n}^{2}}
$$

Where the rate of fines production is $\dot{m}_{\text {fines }}, \gamma$ is the specific free surface energy, and $\dot{m}_{\text {solids,in }}$ is the solids feed rate into the cyclone. The efficiency $\eta$ is assumed to be a function of the solids loading $\mu$, i.e., the ratio of the solids to gas flow rates:

$$
\mu=\frac{\dot{m}_{\text {solids }, \text { in }}}{\rho A_{\text {in }} U_{\text {gas }, \text { in }}}
$$

Where $\rho_{\text {gas }}$ is the gas density and $A_{\text {in }}$ is the gas inlet cross sectional area. The efficiency relation is based on a power law:

$$
\eta_{c}=C \mu^{n}
$$

With $C$ being a constant and $n$ being determined from experiments to be $n \approx-0.5$. Thus, the rate of production of fines is then

$$
\dot{m}_{c, a b r}=C_{c y c} \dot{m}_{\text {solids }, \text { in }} \mu^{-0.5} U_{g a s, i n}^{2}
$$

Where $C_{c y c}=\frac{C}{2 S_{m i} \gamma}$. The authors state that the constant $C_{c y c}$ is only a function of the properties of the catalyst, mainly the material's specific surface free energy, and their subsequent experiments using cyclones of different geometries show this [11]. The model assumes 
the main mechanism behind attrition is abrasion, so at a gas inlet velocity above a threshold impact velocity, the model under predicts the attrition rate due to the fragmentation mechanism [11]. Tamjid et al. use the Reppenhagen and Werther model to predict attrition from CFD simulations based on the velocity of particles at each point in the cyclone [67].

\subsubsection{Impact attrition}

The Ghadiri's attrition model described previously in Section 3.4 accounts for two different mechanisms of attrition, namely chipping and fragmentation with the former occurring at impact velocities between $4 \mathrm{~m} / \mathrm{s}$ and $13 \mathrm{~m} / \mathrm{s}$ and the latter above $13 \mathrm{~m} / \mathrm{s}$. It is assumed in this model that the particles produced by attrition are spherical. The respective equations for calculating smaller part of particle sizes produced by the two mechanisms are [68]:

for chipping:

$$
d_{1}=\left(\alpha \frac{\rho_{p} U_{p}^{2} d_{p}^{4} H}{K_{c}^{2}}\right)^{\frac{1}{3}} 4 \mathrm{~m} / \mathrm{s}<u_{p}<13 \mathrm{~m} / \mathrm{s}
$$

for fragmentation:

$$
\left(3-\xi^{\prime}\right) \frac{d_{1}}{d_{p}}=\ln \left(\lambda^{\prime}\right)-\xi^{\prime} \ln \left(\alpha \frac{\rho_{p} U_{p}^{2} d_{p}^{4} H}{K_{c}^{2}}\right) \quad u_{p} \geq 13 \mathrm{~m} / \mathrm{s}
$$


where $d_{1}$ is the diameter of the smaller part of a particle after impact, $d_{p}$ is the particle size before impact, $\lambda^{\prime}$ and $\xi^{\prime}$ are parameters that are determined experimentally. In the absence of experimental values for these parameters, arbitrary but reasonable values have been selected to simplify the equations to the following form (Lim and Wang, [69]):

$$
d_{1}=\left(2 \times 10^{-4} \rho_{p} U_{p}^{2} d_{p}^{4}\right)^{\frac{1}{3}} \quad 4 \frac{m}{s} \leq U_{p}<13 \frac{m}{s}
$$

And

$$
2 \ln \left(\frac{d_{1}}{d_{p}}\right)=\ln \left(2 \times 10^{-4} \rho_{p} U_{p}^{2} d_{p}\right) \quad U_{p} \geq 13 \frac{\mathrm{m}}{\mathrm{s}}
$$

The diameter of the bigger particle, $d_{2}$, obtained by subtracting the smaller particle from the mother particle size is calculated by:

$$
d_{2}=\left(d_{p}^{3}-d_{1}^{3}\right)^{\frac{1}{3}}
$$

The contact force, $F$, under impact condition can be given by Newton's law as:

$$
F=m_{p} a=m_{p} \frac{d U_{p}}{d t}
$$

Based on two point difference method, the acceleration can be approximated as [21]:

$$
\frac{d U_{p}}{d t} \cong \frac{U_{p}}{t_{p}}
$$


Where $t_{p}$ is the peak contact time, i.e. the impact time at which the force reaches its peak value.

$$
F=m_{p} \frac{U_{p}}{t_{p}}
$$

For elastic contact, the peak contact time can be obtained as [70]:

$$
t_{p}^{e}=1.27\left(\rho_{p}\left(\frac{1-v^{2}}{E}+\frac{1-v_{t}^{2}}{E_{t}}\right)\right)^{\frac{2}{5}} u_{p}^{-\frac{1}{5}} d_{p}
$$

where $E$ and $v$ are the Young's modulus and Poisson ratio of the material. If the target is more rigid than the projectile, the peak elastic time can be approximate by $\frac{1-v_{t}^{2}}{E_{t}} \approx 0$.

According to the Hertz model [71], the normal contact force acting on a sphere during elastic collision is proportional to its diameter and the deformation:

$$
F=\frac{4}{3} d_{p}^{\frac{1}{2}} l^{\frac{3}{2}} \frac{E}{1-v^{2}}
$$

For elastic-plastic contact, the peak contact time dominated by plastic flow and defined as (Zhang, [70]):

$$
t_{p}^{e p}=\frac{1}{2} \sqrt{\frac{\pi m_{p}}{P d_{p}}}=\frac{1}{2} \sqrt{\frac{\pi m_{p}}{H d_{p}}}
$$

where $P$ is the mean contact pressure. 
In terms of predicting particle fragmentation, the particle velocity is perhaps the most significant variable. Chen et al. developed the following empirical correlation for estimating the particle impact velocities as [72]:

$$
U_{p}=\left(\left(a_{1} T+a_{2}\right) \ln \left(d_{p}\right)+\left(a_{3} T+a_{4}\right)\right) U_{g}
$$

where $T$ is the impact temperature, and $a_{1}, a_{2}, a_{3}, a_{4}$ are empirical coefficients, whose fitted values are $-7.9 \times 10-5 \mathrm{~K}^{-1},-0.18,-7.2 \times 10-4$ $\mathrm{K}^{-1}$ and -0.82 . vanLaarhoven et al. give a value of simplified particle impact velocity as $0.7 U_{g}$ [73]. However, there is also threshold impact velocity for the attrition which is the minimum velocity to apply to a particle to cause failure and is given by [74].

$$
U_{p 0}=\left(\frac{4.99}{\pi \rho_{p}}\right)^{\frac{1}{2}}\left(\frac{1-v^{2}}{E}\right)^{\frac{1}{3}}\left(\frac{\pi \sigma_{c}(28+20 v)}{84}\right)^{5 / 6}
$$

where $\sigma_{\mathrm{c}}$ is critical fracture or tensile stress in pascals $(\mathrm{Pa})$.

The collision frequency of the particle (the number of collisions undergone by a single particle per unit of time) in the dense-phased fluidized bed can be written as [75]:

$$
f_{\text {coll }}=\frac{6 \sqrt{2}(1-\epsilon) U_{p}}{d_{p}}
$$

where $\varepsilon$ is the voidage in the dense region.

To describe the particle's breakage probability, the following equation was used [76]: 


$$
P_{\text {break }}=e^{-\frac{C_{b r}}{d_{p} U_{p}^{2}}}
$$

where $C_{b r}$ is the breakage constant that depends on the material properties and needs to be determined empirically and a value of 0.21 $\mathrm{m}^{3} / \mathrm{s}^{2}$ is given for a coke particle [76].

\subsubsection{Population balance modeling}

For a system consisting of particulate solids, a population balance can be used to keep track of the fate of particles in a certain size class as a function of time or degree of attrition. This is particularly important for systems with multi-modal particle size distributions, such as fluidized bed combustion or chemical looping combustion, where solid fuels are mixed with attrited bed material or oxygen carrier [77, 78]. A population balance consists of mass balances within size classes, whereby attrition can cause larger particles to shrink, causing them to disappear from a size class and appear in one or many smaller size class. The balance for a size class consists of a breakage rate function and a particle selection function. The breakage rate function $S_{i}$ acts as a kinetic constant that describes how quickly a particle undergoes attrition from a certain size class $i$, while the particle selection function $b_{i, j}$ describes what fraction of the original particle size goes into which smaller size class. Mathematically, this can be described, for a linear, time-invariant system, for indices $1 \leq j \leq i \leq N$, with $i$ consisting of finer particles than $j[79]$,

$$
\frac{d m_{i}}{d t}=-S_{i} m_{i}+\sum_{j=1}^{i-1} S_{i} b_{i, j} m_{i}
$$


where $m_{i}$ is the mass of size class $i$ as a function of time. The index of 1 consists of the coarsest particles, while index of $\mathrm{N}$ consists of the finest particles. Some restrictions on the breakage rate and the breakage distribution functions are as follows, due to the conservation of total particulate mass. First, particles in the finest size class cannot disappear, so $S_{N}=0$. Furthermore, excluding the possibility for agglomeration, fine particles cannot grow and move into larger classes, and because of the conservation of mass, the sum of the mass fractions that describe how the particle breaks need to add to one [79]:

$$
\sum_{i=j+1}^{N} b_{i, j}=1
$$

Thus, with known breakage kinetics $S_{i}$ and distribution $b_{i, j}$, the mass fraction of size class $i$ can be determined at any time by solving the series of differential equations, given the initial condition of $m_{i}(t=0)=m_{i 0}$. This model can also be modified to have time-variant terms, kinetics based on Gwyn's equation instead of first-order dependence, and include changes in density and chemical reaction [80,77].

The utility of the population balance is that it can be combined with the forces and velocities of a discrete element method (DEM) model to determine a final particle size distribution. The breakage rate and distribution terms can be determined from experiment. Alternatively, the kinetic parameter can be determined based on impact experiments and related to the material properties of the expression of Vogel and Peukert [52]. The breakage rate constant for this is, based on the added energy applied evenly to all particle size classes,

$$
S_{i}=f_{m a t} d_{p} \sum_{l=1}^{L} f_{c o l l, i, l}\left(W_{m, l}-W_{m, m i n, i}\right)
$$


With $f_{\text {coll,i,l }}$ being the collision frequency, $W_{m, l}$ being the energy of the $l$ th collision, and $f_{m a t}$ and $W_{m, m i n, i}$ being material properties [83]. The breakage distribution function can be described by the expression from Broadbent and Callcott:

$$
b_{i, j}=\frac{1-\exp \left(\frac{d_{p, j}}{d_{p, i}}\right)}{1-e^{-1}}
$$

where $d_{p, i}$ and $d_{p, j}$ are the particle sizes before and after breakage [51]. Once these are known or estimated, they can be placed into a DEM model for finding the particle size distribution as a function of time.

Kramp et al. simulated a steady-state $50 \mathrm{~kW}_{\text {th }}$ gaseous fuel process based on the laboratory scale and a $100 \mathrm{MW}$ th gaseous fuel CLC process based on a potential commercial scale unit [78]. Three locations for attrition were used in this work: cyclone, grid jets, and bubbling bed. Since the attrition constants were not known for the oxygen carriers in question, representative constants were chosen from VPO and FCC catalysts from small scale laboratory studies. The locations of loss of oxygen carrier from the vessel differed between the scales, where most of the fines elutriated out the fuel reactor at the small $50 \mathrm{~kW}_{\text {th }}$ scale, while at the large scale, most fines were lost from the air reactor cyclone. The main source of the attrition in both the $50 \mathrm{~kW}_{\text {th }}$ and the $100 \mathrm{MW}_{\text {th }}$ processes was due to the cyclones [78]. Unfortunately, the model does not take into account attrition due to reaction.

Since fluidized bed combustion involves different types of particles, such as coal, limestone, sand, etc., a population balance can be used to simulate the different sizes as well as density distributions at different locations. Wang et al. developed a population balance for a coal-fed $12 \mathrm{MW}$ CFB boiler [77]. It includes a shrinking-core kinetic model to determine the average density of a char particle as a function of time, bubbling bed attrition, primary fragmentation of the coal char as it enters the bed, and char combustion. The model also incorporates the 
hydrodynamics of the fluid bed with the core-annular dynamics of the riser to determine the particle size distribution at these regions. Models such as these are helpful for determining the effects of design changes on a CFB boiler, to predict the change in particle size distribution upon changes in geometry, operating conditions, etc. [81]. Others have performed similar analyses on such systems, with similar assumptions but with varying CFB designs [81, 82].

\subsubsection{DEM and attrition}

$\mathrm{Xu}$ et al. used a DEM based approach to model attrition in hopes of providing a DEM-based tool to predict attrition as a screening instrument to help in the selection of catalysts for fluidized beds, risers and cyclone applications [84]. In their work, they setup a DEM simulation of a rectangular jet cup. For the attrition aspects of the model, they used the formulations of Archard [36] and Ghadiri [21] to model abrasion and erosion, respectively. As a result of exercising the model, they found that attrition was dependent on the jet velocity, initial particle size, particle density and the jet cup geometry. They did not assess the effects of the material mechanical properties, factors that will change significantly from one process to another and within a process like chemical looping which has been described above.

\section{Experimental testing}

Traditionally, attrition research has been performed using two approaches, as described by Werther and Reppenhagen [15]. The first and most common approach is a test-facility method, which uses a smaller version of the desired unit that consists of the types of stresses that the large-scale unit would exhibit. An example is a small scale fluidized bed that attempts to mimic a larger scale bed. The resulting model is usually a result of a few key variables, e.g., gas velocity, bed weight, etc., times a bulk system constant which is system and material dependent. This approach works under the assumption that the small laboratory unit will maintain dynamic similarity to the large-scale 
unit; however, this may not necessarily be the case. Furthermore, the bulk constant is unknown without performing experiments. The second approach attempts to consider both the types of stresses and the range of magnitude of stresses exhibited on the particles [15]. The testing apparatus does not necessarily involve simulating the actual components found in the large-scale system. The resulting forceattrition data can be coupled with multiphase fluid mechanical models to obtain the attrition of a large-scale unit.

A number of the parameters described previously can be determined from representative experiments that provide the same types of forces as would be seen in the actual CFB system. Many of the tests are intended to isolate one type of attrition mechanism. Some of the tests, such as nanoindentation, provide more fundamental properties that can be used elsewhere outside of attrition research.

\subsection{Nanoindentation}

Determination of the hardness of non-particulate materials is straightforward by measuring the projected area of the permanent indentation for a given load on a sample of the material [32]. Similarly, the fracture toughness can be determined by performing tensile tests on a material with a known crack size [33]. However, properties in particulate form may deviate from properties in larger sizes or particles bound together in an agglomerate. Thus, a technique is needed that can provide a small enough indenter load and size to fit onto the surface of a particle. Because the creation of tensile samples of the same material as the catalyst powder and the same physical properties is not always possible, an analogous technique is required for fracture toughness. Additionally, since CFB processes are designed to run at high temperatures, the material properties should be tested at the respective temperature, with low partial pressure of oxygen in some cases, since some of these environments are reducing. 
Nanoindentation is a powerful technique that can determine physical properties such as Young's modulus, hardness, and fracture toughness at a small scale [53]. The technique uses a small diamond indenter, such as a Vickers, Berkovich, cubed corner, etc., and sensitive transducers to apply a known loading rate to the sample while continuously measuring the corresponding displacement of the indenter in the sample. From the load displacement curve, the Young's modulus and hardness can be calculated. A representative plot of the load-displacement of an indenter into a material is shown in Figure 8(a). The plot shows the load required to displace the indenter into the surface of the material, and the load required increases due to the increase in the area of contact with the indenter. The testing is usually programmed to stop at a maximum load, the indenter is held for a short period of time, and then the indenter begins the unloading process. Due to the locally plastic nature of the material, a hysteresis effect is observed upon unloading of the sample. The transducers for a nanoindentation instrument are very sensitive, with typical values of resolution for load around $1 \mu \mathrm{N}$ and for depth on the order of angstroms [86].

The technique requires knowledge of the functional relationship between the indenter depth and projected area of the indenter. The projected area can be estimated from experiments that fit data from knowledge of the projected area and the indentation depth [87]. The equation to fit is usually of the form

$$
A\left(h_{c}\right)=C_{0} h_{c}^{2}+C_{1} h_{c}+C_{2} h_{c}^{\frac{1}{2}}+C_{3} h_{c}^{\frac{1}{4}}+C_{4} h_{c}^{\frac{1}{8}}+C_{5} h_{c}^{\frac{1}{16}}+C_{6} h_{c}^{\frac{1}{32}}
$$

Where $h_{c}$ is the actual depth of the probe in the sample. Modern manufacturing techniques of the tip allow for the area calculation truncated to the first two terms [88]. The actual depth of the indenter in the material is smaller than that measured by the displacement 
transducer due to the elastic deflection of the solid surface around the perimeter of the indenter, as shown in Figure 8(b). This is usually calculated based on the mathematics of elastic contact mechanics described for cylindrical indenters by Sneddon.

$$
h_{c}=h-\frac{\epsilon P}{S}
$$

Where $P$ is the load applied to the sample, $S=d P / d h$ is the stiffness of the material at maximum load, and $\epsilon$ is an indenter constant which is roughly 0.75 [87]. By measuring the slope of the unloading curve (i.e., the stiffness) at maximum load and with knowledge of the Poisson ratio and the projected area $(A)$ functionality with displacement, the material parameter Young's modulus $(E)$ can be calculated using the following equation [87].

$$
E_{r}=\frac{E}{1-v^{2}}=\sqrt{\frac{\pi}{4 A}} \frac{S}{\epsilon}
$$

The stiffness can be measured from a linear function tangent to the point of maximum load or by taking the derivative at the maximum load of a least-squares power law relation of the unloading data. From separate experiments that measure the relationship between the displacement of the indenter into the material and the contact area, the hardness of the material can be calculated using the maximum load $P_{\max }$

$$
H=\frac{P_{\max }}{A}
$$

Where the projected area $A=A(h)$ is evaluated at the maximum displacement. 
The nanoindentation technique can also be used to find the fracture characteristics if the load applied to the indenter can be greatly increased to cause the material to crack. For a ceramic material, using knowledge of the crack size, the maximum load applied, and the hardness and modulus, the fracture toughness can be calculated from the following equation:

$$
K_{c}=\beta \sqrt{\frac{E}{H}} \frac{P_{\max }}{c^{\frac{3}{2}}}
$$

where $\mathrm{c}$ is the crack length (according to Figure 9), and $\beta$ is an indenter constant, which for example is 0.0161 for a Berkovich indenter [44]. For such small scales, the load required to crack the material using a Vickers probe is impractical, so a cube-corner probe is often used instead, which lowers the cracking load threshold [89]. While hardness is traditionally assumed to be independent of load applied, care should be taken to indent the material sufficiently enough to prevent the phenomenon of the indentation size effect from providing accurate measurements of the particle [86].

The versatility of the technique can be due to the very small nature of the indenter, allowing for measurement of individual particles and grains. The motivation behind nanoindentation was to determine hardness of thin films where traditional hardness indentation techniques would indent at a depth longer than the thickness of the material [90], so the technique naturally applies well to small particles. The technique has been used at room temperature to deduce the properties for pharmaceutical crystals [91], steam methane reforming catalyst [92], silica [53], and yttria stabilized zirconia [53]. Most importantly, the technique can also measure the material properties in inert environments at high temperatures, which is important for processes such as combustion and oxidation/reduction in 
CLC [93]. A summary of the results of nanoindentation testing for particulate samples is shown in Table 1, which includes information such as the hardness, Young's modulus, and fracture toughness for particulate solids.

Using a Berkovich probe, Viktorov et al. studied the physical properties of hematite, magnetite, and silica for knowledge of the properties of minerals during mining [44].

In order to predict milling behavior on small samples, Taylor et al. tested Young's modulus, hardness, and fracture toughness for various pharmaceutical powders using a Berkovich indenter, with the range of maximum loads programmed to be between 20-150 mN [91]. Good reproducibility was observed for the samples. The hardness measurement was determined to be relatively independent of the applied maximum load for two of the compounds studied (Voriconazole and a compound named "UK-370,106"), but an unnamed compound showed wide variability in hardness. The authors also showed that the fracture toughness equation, which is mainly valid for ceramic equations, was also valid for the powder grains tested in this study. The equation is valid when the ratio of the maximum load applied to the crack length to power of $1.5\left(\frac{P}{c^{1.5}}\right)$ is relatively constant for each test.

Arteaga et al. performed nanoindentation on the $\{100\}$ surfaces of pure dried vacuum (PDV) salt with a nominal size of $500 \mu m$ to compare the effects of various salt processing routes on the relative surface hardness [94]. Each salt sample was separated and dried in one of the following ways: (1) centrifuged, then dried in a fluidized bed, (2) centrifuged, dried, and cooled in a fluidized bed, (3) vacuum filtered and dried in situ (not in fluidized bed). Instead of calculating an exact number for hardness, the authors calculate a hardness index which is defined as the load divided by the plastic depth into the material squared and divided by an indenter constant, viz., $\frac{P}{\delta_{p} k}$, as opposed to dividing the maximum load by the projected area. The resulting index was normalized to values obtained for melt-grown 
crystals at the corresponding plastic depth. The materials that exhibited greatest normalized hardness were those that were processed in a fluidized bed due to work-hardening of the surface of the crystals (microplastic deformations). Beyond an indentation depth of $1000 \mathrm{~nm}$, the vacuum filtered and in situ dried salt exhibited similar hardness to melt-grown salt, while the fluidized bed dried salts exhibited normality closer to a depth of $3000 \mathrm{~nm}$.

Zbib et al. measured the elastic modulus, hardness, and fracture toughness of particulate $(650-2000 \mu m)$ soda lime glass, silica, silicon, barium titanate glass, and yttria-stabilized zirconia for developing a comminution parameter. The hardness and elastic modulus were determined using nanoindentation, but the fracture toughness was determined using a Vickers microhardness device [53].

Couroyer et al. measured the hardness and fracture toughness of spheres of steam methane reforming catalyst, sized 1.7-2.0 mm, using a Vickers indenter [92]. The hardness was ascertained in two ways. The first way was by measuring the indentation on the exterior of the sphere, and the second was by indenting the inside of hemispherical particles. The internal hardness was slightly lower than the external hardness, but the internal hardness exhibited greater variability in hardness over a range of applied loads.

\section{$\underline{5.2 \text { Cyclone }}$}

According to a detailed literature search, it seems that there has been limited research performed on the attrition in a cyclone. The main areas of research are attributed to both Zenz [27] and Werther [11]. Zenz measured the attrition of FCC catalyst in cyclones of three different diameters: 4, 11, and 30 inches. The procedure consisted of passing a load of solids at a given gas flow rate through the cyclone, collecting and mixing the overhead and bottom solids, and sending them through the cyclone again. This procedure was performed 
numerous times to measure the rate of attrition. The overhead solids were recycled to ensure that the cyclone efficiency does not affect the attrition rate [27].

Table 2 summarizes results from cyclone attrition studies, which are reported on a basis of mass of attrited solid per mass of solid fed to the cyclone. The main variables are the inlet gas velocity and the solids loading to the cyclone (mass fraction of solids per fraction of gas).

Reppenhagen and Werther performed extensive studies on FCC catalyst attrition in Stairmand cyclones of nine different geometries, with gas velocities ranging from $8-24 \mathrm{~m} / \mathrm{s}$, and gas to solid ratios ranging from 0.05 to 1 [11]. The work of Reppenhagen and Werther attempted to improve the work of Zenz by studying the FCC catalyst attrition after the catalyst reached steady state attrition. Other work included the study of catalyst attrition in the cyclone coupled with the riser [95].

Figure 10 shows a sketch of their experimental setup. The cyclone was operated using an induced draft suction fan, and solids were fed tangentially into the cyclone due to the suction of the gas outlet. The solids separated by the cyclone were collected in a hopper, and any mother particles unintentionally separated out the top, if any, were collected by a sieve filter in the gas outlet. The test consisted of passing the bottom solids collected through the cyclone up to 60 times to measure a steady state rate of attrition.

Results from the testing showed that the gas velocity and the solids to gas ratio are the most important variables in the steady state attrition process, while the cyclone geometry was not important. At higher velocities, the attrition mechanism is no longer solely via abrasion, and the measured attrition is greater than that predicted by their abrasion model. The effect of different entrance lengths to the cyclone and the shape of the entrance showed minimal variability in attrition rate. The shape and size of the cyclone did not play a large role in the attrition rate [11]. 


\section{$\underline{5.3 \text { Fluid bed }}$}

The laboratory fluidized bed can take several forms. For studying jet attrition, the gas distribution will either consist of a single orifice [97] or three orifices, such as in the ASTM D5757 test [9]. The original fluidized bed attrition testing was developed and performed by Forsythe and Hertwig and consisted of a distributor with a single orifice [97]. Additionally, to only study bubbling attrition, the plate is replaced with a perforated plate, such as by Ray et al. [30]. The obvious use of the fluidized bed attrition unit is to monitor the attrition due to bubbling or grid jets, but fluidized bed tests have also been used for attempting to predict the susceptibility of attrition in pneumatic conveying lines [15]. A summary of prior work can also be found in reviews such as that by Bemrose and Bridgwater [14].

Ray et al. studied limestone attrition (300-1000 micron feed size) in a small fluidized bed consisting of a porous plate distributor [30]. They developed a multi-component attrition model to determine the relative rate of attrition between different particulate species, comparing the attrition of different sizes of limestone (high degree of attrition) and silicate sand (low degree of attrition) to validate their model.

Wu et al. studied the attrition of three different commercial FCC catalysts and determined that during the unsteady state period, fragmentation is prevalent, and the rate of surface wear changes due to the irregular shape of the broken fragments. After a period of time, the rate of fragmentation decreases, and abrasion is the main mechanism of attrition, and the rate of attrition is at a steady state [98].

Additionally, there have been attempts to correlate the attrition of a material in a fluidized bed to the solid mechanical properties, usually in the form of tailored agglomerates with known material properties. Mullier et al. state that for the attrition of agglomerates with known mechanical properties in a fluidized bed, the attrition rate was a function of the inverse of the fracture toughness [99]. 
Beside the simple room temperature testing, laboratory scale fluidized bed attrition has also been tested at high temperature and with reaction. Yao et al. have tested five limestones at $850^{\circ} \mathrm{C}$ in a fluidized bed under calcining and sulfating conditions [100]. The gas velocity was adjusted to around $0.1-0.2 \mathrm{~m} / \mathrm{s}$ so as to minimize the attrition due to high velocity. The particle size distributions of the fluidized bed at various times were compared to samples heated in a muffle furnace to indicate the degree of thermal shock on the attrition. By replacing the fluidizing gas with $\mathrm{CO}_{2}$, the effects of thermal shock and abrasion in the fluidized bed could be isolated from calcination. Results indicate that the calcination process is the greatest cause of limestone attrition by fragmentation, since the particle size distribution of the limestone fluidized in $\mathrm{CO}_{2}$ at high temperature was nearly the same as the fresh limestone. They also indicated that sulfation decreases the amount of attrition.

For chemical looping combustion applications, Brown et al. studied the effects of bubbling fluidization on pure iron oxide (hematite) and alumina-supported copper oxide under three different hot conditions at $850{ }^{\circ} \mathrm{C}$ : (1) fluidization with air, (2) single reduction stage with carbon monoxide/carbon dioxide, and (3) oxidation-reduction over 10 cycles, as well as an $11^{\text {th }}$ reduction after sieving and reheating the particles [101]. Attrition was measured by the elutriation rate, using a pair of filters at the gas outlet of the fluid bed, switching between new and used periodically throughout the run. The first set of experiments showed the typical exponential decay of the time dependence of attrition by abrasion. The second set showed the rate of attrition at multiple points during reduction of the oxygen carriers. For the unsupported iron oxide, the attrition increased gradually through the reduction phase, then decreased with time after the reaction stopped. For the alumina-supported copper oxide however, the attrition rate dropped as a function of time, even during chemical reaction. The multi-cycle testing showed that the unsupported iron oxide attrition rate increased dramatically with increased oxidation-reduction cycles, while the supported copper oxide decreased, for the most part. The magnitudes of the attrition rates for the different materials 
were also vastly different, with unsupported iron oxide having a peak attrition rate of around $110 \mathrm{mg} / \mathrm{min}$ during the $10^{\text {th }}$ oxidation cycle, while the alumina-copper oxide having a peak of around $2.7 \mathrm{mg} / \mathrm{min}$ during the first reduction cycle [101].

A summary of the results of various fluidized bed attrition tests is shown in Table 3, which includes the unit dimensions, operating conditions, and materials used. The attrition rate reported in the table is in fraction of total bed attrited per second, which was directly reported in the papers cited or estimated by the authors of this work from the corresponding papers. It can be noted that the factors presented in this paper cause a greater extent of attrition. For example, test runs at room temperature produced a lower attrition rate than those tests at high temperature, which in this table is most likely due to the reaction chemistries involved (such as calcination, sulfation, etc.). Additionally, the type of reaction chemistry affects the attrition rate. Reactions that cause the loss of species such as $\mathrm{CO}_{2}$ during calcination in FB combustion and lattice oxygen during reduction in CLC tend to cause higher attrition rates, while reactions that add to the lattice structure of the particles such as sulfation cause the attrition rate to be hindered. Finally, grid jets in fluidized beds cause a great degree of localized attrition, so the attrition rate results will depend on the size of the bed compared to the size of the jet.

\subsection{Annular Shear cell}

The annular shear cell, as shown in Figure 11, consists of a circular trough that holds particulate sample, with grooves at the bottom. Placed on top of the sample is a weighted plate that applies a known pressure on the material, and the bottom circular trough rotates at a certain angular velocity and with a known torque. Such a device has been historically used to determine the coefficient of friction between a surface and a powder. A time later, as described by Paramanathan and Bridgwater, the procedure was modified to measure the rate and extent of comminution of various powders [55]. The modified procedure consists of applying a shearing force to the particulate sample 
due to the rotation of the cup. At different known shear distances, which are known from the average diameter of the shear cell and the number of rotations performed by the cell, the experiment is stopped and the particle size distribution is measured. The shear distance, load applied, and the breakage rate are used to derive parameters for breakage correlations, such as described by Gwyn [56].

\section{$\underline{5.5 \text { Impact testing }}$}

Particulate impact tests are used for determining the resistance to impact, the size of the daughter products, and the threshold velocity at different velocities. Usually below the threshold velocity, the particle will not experience significant breakage. The test is also an indicator of the degree of friability the material may exhibit. Traditionally, these tests have been performed using a drop tube, whereby the particle free-falls to a hard target below, and the particle size distribution is measured post mortem [7]. However, researchers such as Yuregir et al. have developed an apparatus that utilizes an air-blown eductor to convey particles, usually one at a time, at a target [84]. This allows for a much greater range of impact velocities. The apparatus used is shown in Figure $\mathbf{1 2}$ and consists of an eductor which allows solids to be fed into the air stream, a filter for the fines collection, and a camera or velocimetry device to capture the particle velocity upon impact.

Zhang and Ghadiri studied the impact attrition of cut crystals of $\mathrm{MgO}, \mathrm{NaCl}$, and $\mathrm{KCl}$ over $20 \mathrm{impacts}$ at velocities of $4.3-8.4 \mathrm{~m} / \mathrm{s}$. They were able to extract the proportionality factor for impact attrition, which was around $1.2-1.7 \times 10^{-4}$ for $\mathrm{MgO}, 4.3-8.2 \times 10^{-4}$ for $\mathrm{NaCl}$, and 1.0-4.6 $\times 10^{-4}$ for $\mathrm{KCl}$ and show that the impact attrition follows this model [104].

Meier et al. studied the impact attrition of pharmaceutical powders for the purpose of predicting grinding characteristics [51]. As opposed to works like Zhang and Ghadiri, Meier et al. impacted multiple particles at the same time, in batches, and studied the sizes post mortem. 
This has the challenge of determining the actual impact velocity, but it is a necessity for fine powders, since individual particles cannot be individually separated easily.

Chen et al. performed impact studies on limestones in the temperature range of $25-580^{\circ} \mathrm{C}$ and conveying gas velocities of $20-100 \mathrm{~m} / \mathrm{s}$ [105]. In their experiments, they noted that particle breakage occurred less frequently at higher temperatures, and they claim this is due to the decreased impact velocity and the increased threshold fragmentation velocity at higher temperatures [105]. This has the effect that at higher temperatures, polycrystalline materials such as catalysts and oxygen carriers will be more resistant to impact and fracture at higher temperatures but more susceptible to other mechanisms such as abrasion and thermal or chemical stress.

For chemical looping combustion, Brown et al. studied impact attrition of iron oxide in the form of unsupported hematite and aluminasupported copper oxide, both after one and after ten reduction-oxidation cycles described previously in the fluidized bed experiments [101]. Hematite and magnetite particles (reduced form) after one reaction cycle showed a reasonable impact attrition resistance, with $4.6 \%$ and $11.7 \%$ of the original particle mass being fragmented at $45 \mathrm{~m} / \mathrm{s}$, respectively, but after $10^{\text {th }}$ oxidation and $11^{\text {th }}$ reduction for hematite and magnetite, such as at $38 \mathrm{~m} / \mathrm{s}$, a greater than 97\% mass fragmentation occurred [101]. Meanwhile, the alumina-supported copper oxide showed a much greater resistance to impact fragmentation, whereby the breakage after the $10^{\text {th }}$ oxidation and $11^{\text {th }}$ reduction cycles is around $18 \%$ of the original mass [101]. This indicates the importance of using a support for oxygen carriers.

The impact velocity for solids depends on the properties of the solid and the conditions present, such as temperature and partial pressure of oxygen. Ghadiri found that the mother salt crystals tend to begin to chip around $4 \mathrm{~m} / \mathrm{s}$ and undergo fragmentation around $13 \mathrm{~m} / \mathrm{s}$ [70]. Chen et al. found that limestone particles begin to fragment at velocities around 8.5-13.5 m/s from $25-580^{\circ} \mathrm{C}$ [104], and Reppenhagen and 
Werther found that the abrasion model for attrition in a cyclone for FCC powder begins to deviate due to fragmentation of the particles around $20 \mathrm{~m} / \mathrm{s}$ [11]. Thus, the threshold velocity could be considered a material parameter.

\subsection{Jet Cup}

The Grace-Davidson jet cup is a common device used to compare the attrition characteristics of fine catalysts, usually in small quantities [8,15]. As shown in Figure 13, it consists of a cup that holds the catalyst sample, with a tangential gas inlet that impinges a small but high velocity gas jet, causing the particles to impact other particles and the walls of the cup. The gas and solids exit the cup through a disengagement section, allowing for gravity to separate most of the particles, while the remaining particles are captured with a filter, either internally or external to the device. This provides a good screening tool for catalyst development, since only a small amount is required for testing [15]; however, smaller sample can result in larger measurement error [10]. Additionally, there is no standard for the dimensions of a jet cup nor is there a standard gas velocity [10]. The usual value that comes out of this test is the attrition index, which is the mass of fines generated below either 44 microns or 20 microns divided by the mass of the unattrited sample. This is mainly prevalent for Group A particles. The Grace-Davidson jet cup usually is considered to represent the attrition in a cyclone in a CFB. Additionally, the incoming air is usually humidified to prevent the particles from sticking to the walls due to static electricity [10].

Amblard et al. studied the attrition characteristics of a Geldart Group A FCC catalyst and a Group B CLC mineral oxygen carrier, and their work attempted to develop a new attrition index for Group B particles, which are prevalent in CLC, since breakage by fragmentation of Group B particles is not below 44 microns [106]. Their new attrition index involved measuring the difference in particle size distribution before and after attrition, named the total particles generated index. This parameter tended to increase dramatically after a certain jet 
velocity, indicative of the transition from abrasion to fragmentation. CFD analysis using Barracuda showed that in order to have the same mechanical flow patterns of the particles, the volume of solids in the cup needed to be constant, as opposed to equal weight [106].

Ryden et al. tested 25 different oxygen carrier materials in a conical jet cup unit as part of an assessment for the selection of oxygen carriers for CLC, both before and after oxidation and reduction reactions [10]. They ran conical jet-cup testing using $5 \mathrm{~g}$ of material with a jet velocity of around $94 \mathrm{~m} / \mathrm{s}$, weighing the filter every 10 minutes. Many of the used oxygen carriers exhibited a linear attrition rate, while many of the fresh oxygen carriers, which consisted of perhaps rough surfaces, tended to show a time dependence of attrition. They conclude that iron- and nickel-based oxygen carriers supported on alumina-type supports $\left(\mathrm{NiAl}_{2} \mathrm{O}_{4}, \mathrm{MgAl}_{2} \mathrm{O}_{4}\right)$ and perovskite materials had a higher resistance to attrition after reaction, while copper based and $\mathrm{ZrO}_{2}$ and $\mathrm{Mg}-\mathrm{ZrO}_{2}$ supported material showed lower resistance to attrition. They attribute the resistance of attrition to the lower porosity of the material. Finally, with exception to crushing strengths above $2 \mathrm{~N}$, they indicate there was not a strong correlation between the particle crushing strength and the performance in the larger continuous chemical looping units, but the jet cup correlated better, despite the fact that chemical and thermal stresses were not applied to the particles in the room-temperature jet cup experiments [10].

The design philosophy of a jet cup should be to cause as much of the sample to undergo attrition conditions. Therefore, Cocco et al. looked at various design changes to the original Grace-Davidson jet cup to determine which one minimizes the degree of particle stagnation, and they found that a conical jet cup with a single tangential inlet produced the most active material [107]. Tests were run with both an FCC catalyst and a proprietary catalyst, and the gas velocities ranged from 76 to $274 \mathrm{~m} / \mathrm{s}$. The cups were made of Plexiglas to be able to monitor the solids motion externally. They also simulated the original Davidson jet cup using CFD to monitor where regions of particulate trauma were high and low, and they indicate that the particles tend to hit the wall rather than slide over it. Furthermore, the particulate 
velocity in the vicinity of the jet was only around $12 \%$ of the gas velocity. For the simulation of the conical jet cup, the particulate trauma was higher as well as the collisional frequency [107]. Similar to work by Ryden et al., Cocco et al. compared the jet cup testing to attrition in an actual unit, namely a 12" fluidized bed with three recycle cyclones, and the conclusion showed limited correlation between the cylindrical jet cup performance and that at the larger-scale [107].

\section{Conclusions}

While attrition of particulate solids in CFB systems is a complex phenomenon, it is nonetheless important to understand in order to develop an economically feasible technology. As noted, this is especially true for new technologies like chemical looping that are based on reacting engineered materials that are expensive. This paper brings out five main points related to free surface energy models, lack of dynamic similarity in small scale test units, the potential benefits to new testing techniques like nanoindentation, the need for high temperature data and most critically - the need for a quantitative attrition predictive tool. Figure $\mathbf{1 4}$ summarizes a potential approach based on the concepts described in this work. The approach begins with an assessment of what the type of attrition mechanism would be in a certain unit operation, whether it is via abrasion or fragmentation. With the mechanism determined, a wear or fragmentation model can be utilized, whereby the rate or extent of breakage is a function of the hydrodynamics exhibited in the unit operation, such as the normal loads, wear distances, velocities etc., applied to the particle, which are a function of the geometries and flow rates. With knowledge of the particulate material properties, such as the hardness and fracture toughness, determined from the techniques described in this paper, and with knowledge of the severity coefficients in the wear and fragmentation models, the steady state rate of mechanical attrition can be determined. 
As can be seen from the section on attrition modeling, successful models have been developed based on an energy transformation between the input kinetic energy and the output into making new surface. The main material parameter is the free surface energy, which is the energy required to create new surface area of a solid material. While deriving the attrition rate based on an energy balance approach, even though the assumptions may produce oversimplifications, is a wise approach, the models produced require that knowledge of the efficiency and proportionality terms. These at the present are only derived, in a bulk coefficient term, from the corresponding experiments on the unit operation.

While there exist a variety of small-scale laboratory apparatuses that attempt to characterize or even measure attrition, such as the Davidson jet cup, the ASTM-D 5757 jetting bed, etc., small scale work needs to be performed under the same conditions that particles would experience in the larger unit. For example, if the attrition rate of a solid needs to be estimated at a bend in a pneumatic conveying line, parameters such as the impact velocity, the stress exerted on the particle, and sliding distance in the bends need to be matched, but the unit operation does not. In other words, the small-scale experiment should maintain dynamic similarity to the mechanisms of particle attrition that would occur at large-scale [15].

There exist many laboratory techniques that can measure material properties, but the challenge is to determine these properties for small particles, which may be different than for the agglomerated or bulk form of the material. However, technologies such as microindentation and nanoindentation can provide an estimate of these properties, whereby the hardness and fracture toughness can be input into the abrasion and erosion relations such as from Archard and Ghadiri and Zheng to estimate the rate of attrition. Additionally, these parameters need to be ascertained at the design temperatures of the systems. Higher temperatures result in higher fracture toughnesses, resulting in higher threshold impact velocities for ceramic catalyst materials, yet the hardness causes the material to undergo abrasive 
wear more readily. Higher temperatures also bring the potential for greater thermal stress, particularly due to the feeding of cold makeup solids.

Additionally, the vast majority of attrition models developed provide quantitative emphasis on mechanical causes, but there are no models that can predict the extent of attrition based on chemical stress. This is especially important for fields such as chemical looping combustion, where oxygen from the solid metal oxide carrier oxidizes the carbonaceous fuels, causing changes in the lattice structure of the oxide. Thus, future work should place a focus on predictive attrition modeling of this phenomena.

\section{Disclaimer}

This project was funded by the Department of Energy, National Energy Technology Laboratory, an agency of the United States Government, through a support contract with URS Energy \& Construction, Inc. Neither the United States Government nor any agency thereof, nor any of their employees, nor URS Energy \& Construction, Inc., nor any of their employees, makes any warranty, expressed or implied, or assumes any legal liability or responsibility for the accuracy, completeness, or usefulness of any information, apparatus, product, or process disclosed, or represents that its use would not infringe privately owned rights. Reference herein to any specific commercial product, process, or service by trade name, trademark, manufacturer, or otherwise, does not necessarily constitute or imply its endorsement, recommendation, or favoring by the United States Government or any agency thereof. The views and opinions of authors expressed herein do not necessarily state or reflect those of the United States Government or any agency thereof. 


\section{Acknowledgements}

This research was supported in part by an appointment to the National Energy Technology Laboratory Research Participation Program, sponsored by the U.S. Department of Energy and administered by the Oak Ridge Institute for Science and Education.

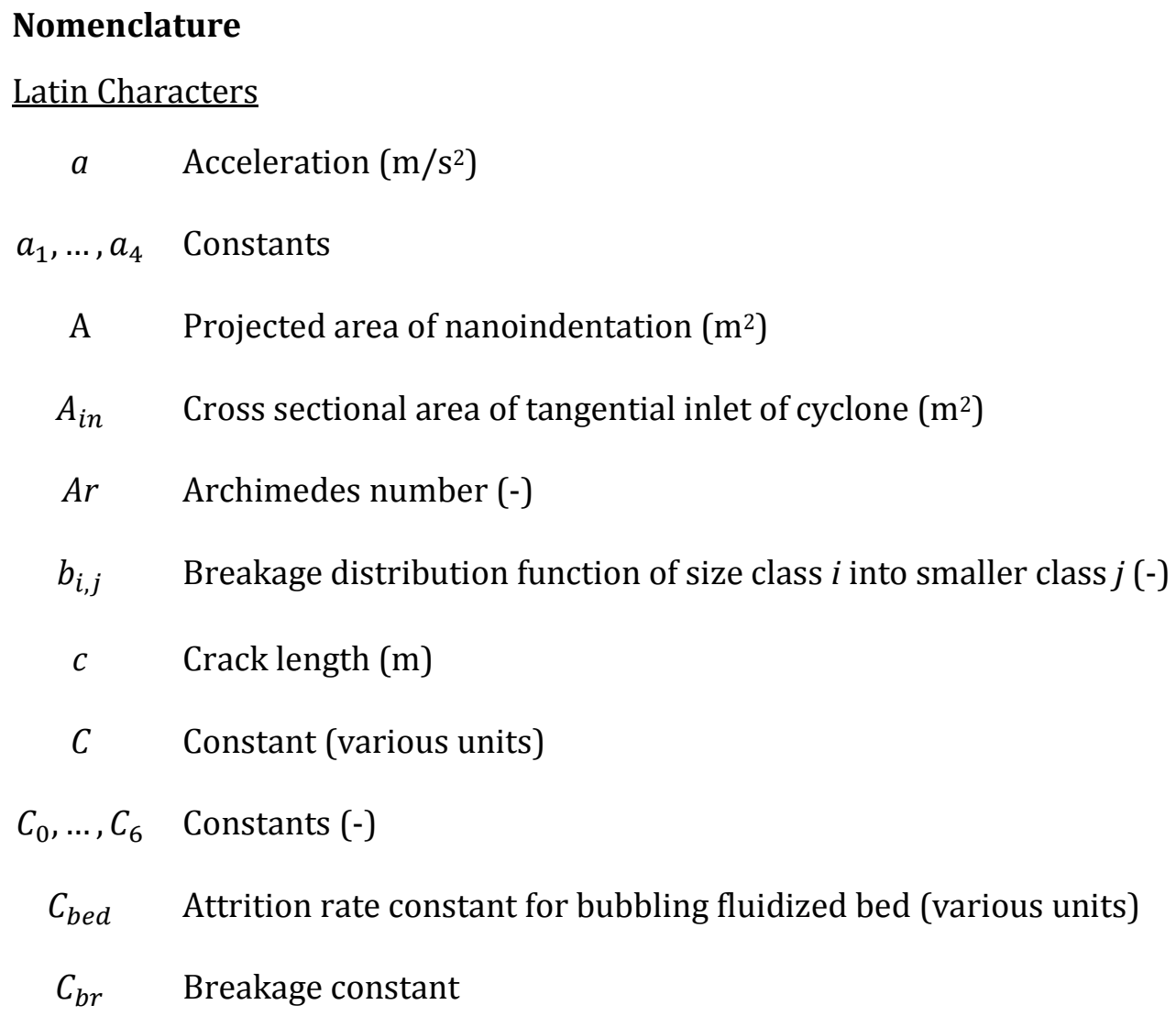




$\begin{array}{cl}C_{c y c} & \text { Cyclone attrition constant } \\ D & \text { Diameter of bed (m) } \\ D & \text { Attrition diffusivity }\left(\mathrm{m}^{2} / \mathrm{s}\right) \\ d_{1} & \text { Diameter of smaller particle after impact (m) } \\ d_{2} & \text { Diameter of larger particle after impact (m) } \\ d_{o r} & \text { Orifice diameter (m) } \\ d_{p} & \text { Particle size (m) } \\ d_{p, i} & \text { Particle sizes before breakage (m) } \\ d_{p, j} & \text { Particle sizes after breakage (m) } \\ d_{p 0} & \text { initial particle size (m) } \\ E & \text { Young's modulus (Pa) } \\ E & \text { Energy (e.g., grinding) (J) } \\ \dot{E}_{b, e x} & \text { Excess energy rate added to fluidized bed (J/s) } \\ \dot{E}_{c, a b r} & \text { Energy to abrade particles in cyclone (J/s) } \\ \dot{E}_{c, a b r} & \text { Kinetic energy input into cyclone (J/s) } \\ \dot{E}_{k i n} & \text { Kinetic energy added to fluidized bed (J/s) } \\ & \end{array}$




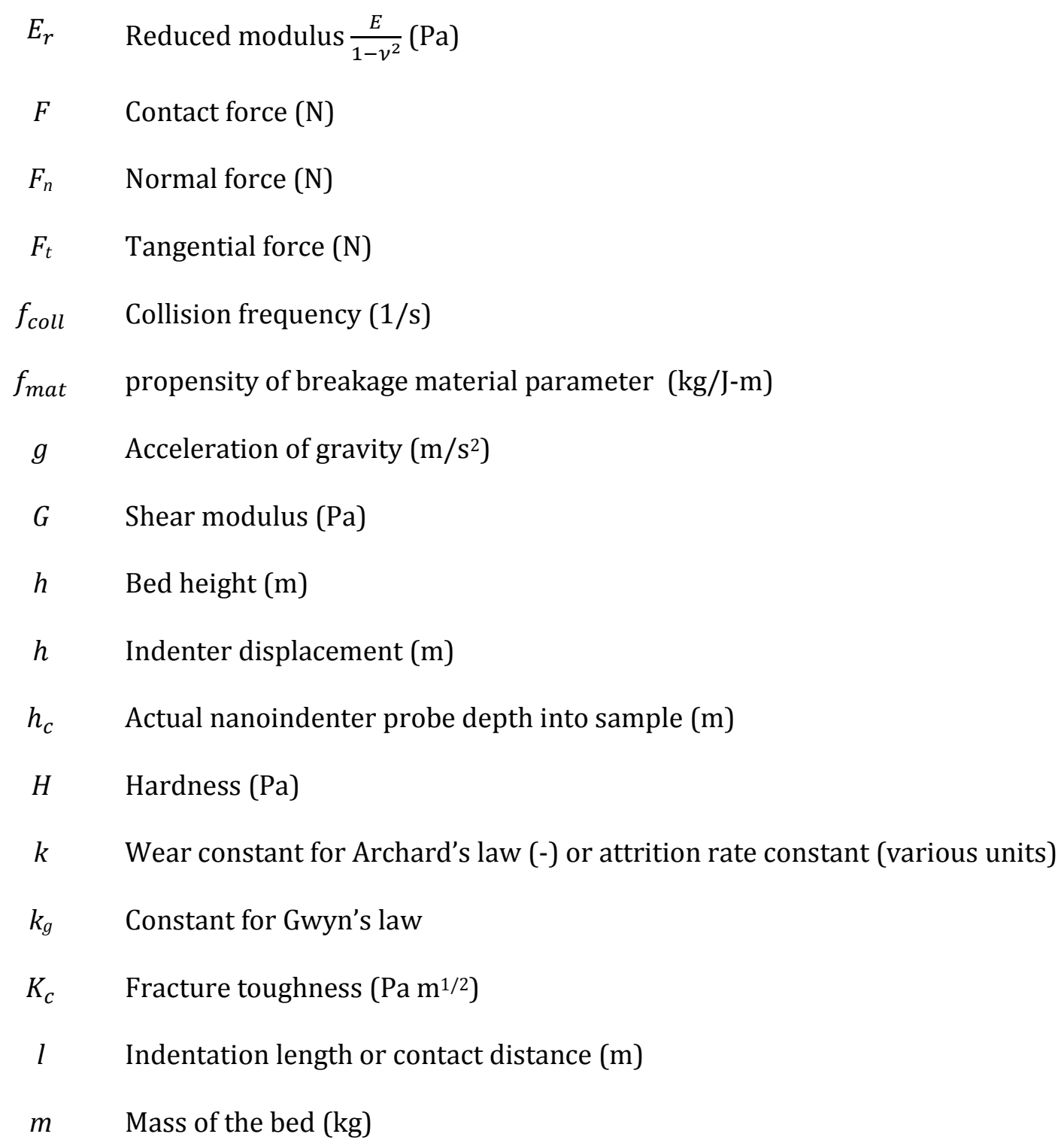




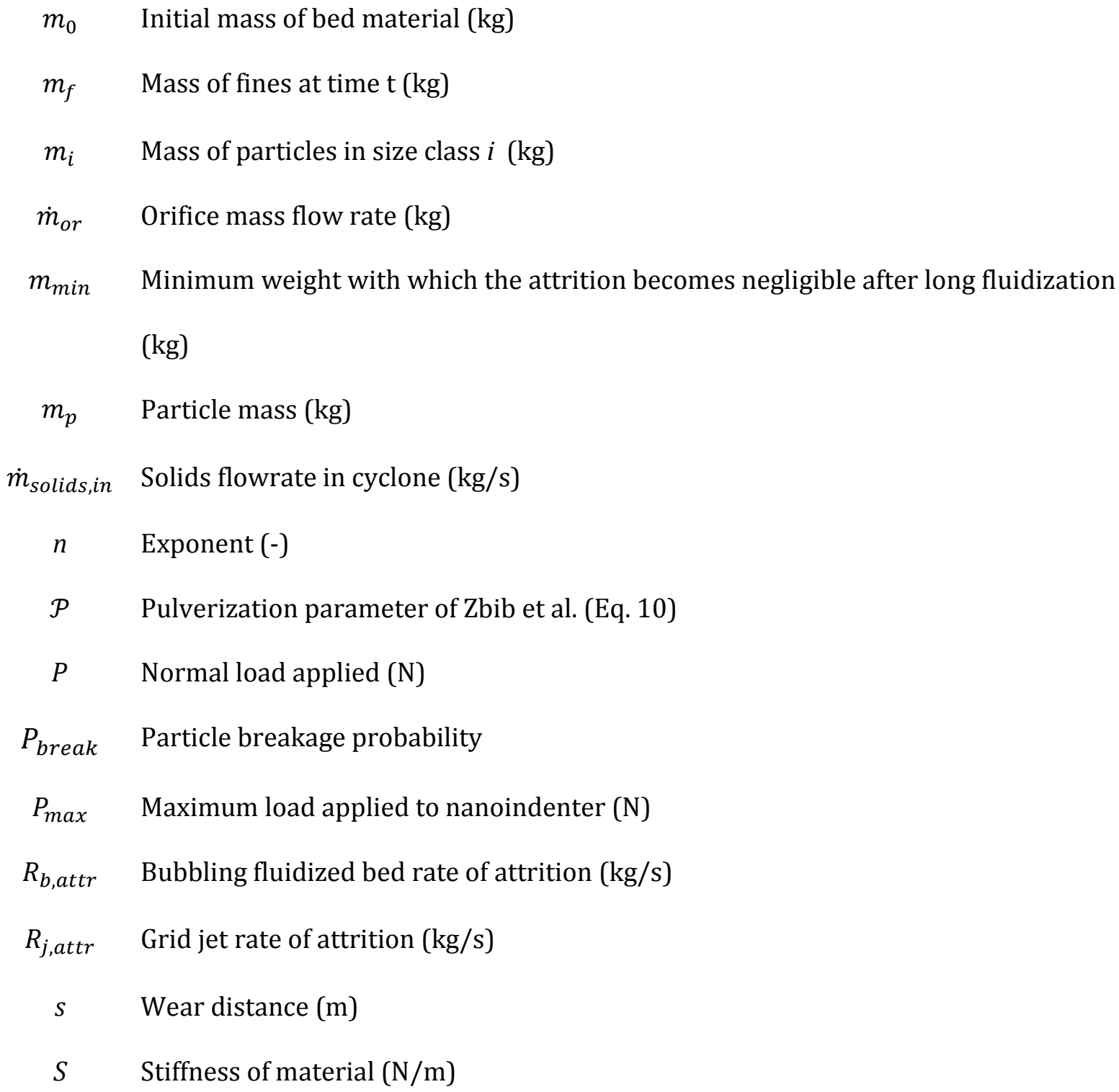


$S_{i} \quad$ First-order breakage rate kinetic term of size class $i(1 / \mathrm{s})$

$S_{m i} \quad$ Specific surface area of the abraded fines $\left(\mathrm{m}^{2}\right)$

$t_{p} \quad$ Peak contact time (s)

$t_{p}^{e} \quad$ Elastic peak contact time (s)

$t_{p}^{e p} \quad$ Elastic-plastic peak contact time (s)

$T \quad$ Impact temperature (K)

$U \quad$ Superficial gas velocity $(\mathrm{m} / \mathrm{s})$

$\bar{U} \quad$ Axial-averaged velocity $=\int_{0}^{h} U_{g} d z / \int_{0}^{h} d z(\mathrm{~m} / \mathrm{s})$

$U_{g a s, \text { in }} \quad$ Entrance gas velocity in cyclone $(\mathrm{m} / \mathrm{s})$

$U_{\text {impact }}$ Impact velocity (m/s)

$U_{m f} \quad$ Minimum fluidization velocity $(\mathrm{m} / \mathrm{s})$

$U_{o r} \quad$ Orifice gas velocity $(\mathrm{m} / \mathrm{s})$

$U_{p} \quad$ Particle velocity (m/s)

$U_{p 0} \quad$ Threshold velocity (m/s)

$V_{w} \quad$ Wear volume $\left(\mathrm{m}^{3}\right)$

$w \quad$ Solids concentration (-)

$W_{m, k i n} \quad$ Mass specific kinetic energy of impact $(\mathrm{J} / \mathrm{kg})$ 
$W_{m, \min } \quad$ Minimum mass specific threshold energy (material parameter) $(\mathrm{J} / \mathrm{kg})$

$x \quad$ Spatial parameter for attrition diffusion model (m)

$\underline{\text { Greek Letters }}$

$\alpha \quad$ Proportionality constant for impact attrition expressions (various units)

$\beta \quad$ Nanoindenter constant (-)

$\beta_{\max } \quad$ Maximum fracture energy $\left(\mathrm{J} / \mathrm{m}^{2}\right)$

$\Gamma \quad$ Bubble throughput (-)

$\epsilon \quad$ Voidage in dense region (-)

$\eta_{j, a b r} \quad$ Energy conversion efficiency term (-)

$\lambda^{\prime} \quad$ Experimental parameters for impact attrition $(-)$

$\mu \quad$ Dynamic gas viscosity $(\mathrm{kg} / \mathrm{m}-\mathrm{s})$

$v \quad$ Poisson ratio $(-)$

$v_{t} \quad$ Poisson ratio of target $(-)$

$\rho \quad$ Gas density $\left(\mathrm{kg} / \mathrm{m}^{3}\right)$

$\rho_{p} \quad$ Particle density $\left(\mathrm{kg} / \mathrm{m}^{3}\right)$

$\sigma_{c} \quad$ Critical fracture or tensile stress (Pa)

$\sigma_{p} \quad$ Surface free energy $\left(\mathrm{J} / \mathrm{m}^{2}\right)$ 
$\xi_{w} \quad$ Wear volume per sliding length $\left(\mathrm{m}^{3} / \mathrm{m}\right.$ or $\left.\mathrm{m}^{2}\right)$

$\xi^{\prime} \quad$ Experimental parameters for impact attrition $(-)$

$\zeta \quad$ Fractional loss per impact $(-)$

\section{References}

1. Grace, J.R.; Bi, H.; Golriz, M. “Circulating fluidized beds.” In: Handbook of fluidization and fluid-particle systems, Y.-C. Yang, Ed., Marcel Dekker Inc., New York, NY, 2003.

2. Kunii, D.; Levenspiel, O. Fluidization Engineering, Elsevier, 1991.

3. Adánez, J.; Abad, A.; Garcia-Labiano, F.; Gayan P.; de Diego, L. "Progress in chemical-looping combustion and reforming technologies." Prog. Energy Combust. Sci. 38 (2012) 215-282.

4. Zhang, H.; Degreve, J.; Baeyens, J.; Wu, S.-Y. “Powder attrition in gas fluidized beds.” Powder Technol. 287 (2016) 1-11.

5. Proll, T.; Schony, G.; Sprachmann, G.; Hofbauer, H. "Introduction and evaluation of a double-loop staged fluidized bed system for post-combustion $\mathrm{CO}_{2}$ capture using solid sorbents in a continuous temperature swing adsorption process." Chem. Eng. Sci. 141 (2016) 166-174.

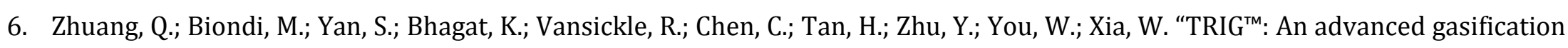
technology to utilize low rank coals for power." Fuel 152 (2015) 103-109.

7. British Materials Handling Board. Particle attrition: State-of-the-art review. Trans tech publications, 1987.

8. Weeks, S.A.; Dumbill, P. “Method speeds FCC catalyst attrition resistance determinations” Oil Gas J. 88 (1990) 38-45. 
9. ASTM, D5757 -11 "Standard test method for determination of attrition and abrasion of powdered catalysts by air jets." American Society for Testing and Materials International, West Conshohocken, PA, 2011.

10. Ryden, M.; Moldenhauer, P.; Lindqvist, S.; Mattisson, T.; Lyngfelt, A. "Measuring attrition resistance of oxygen carrier particles for chemical looping combustion with a customized jet cup." Powder Technol. 256 (2014) 75-86.

11. Reppenhagen, J.; Werther, J. “Catalyst attrition in cyclones.” Powder Technol. 113 (2000) 55-69.

12. Ulerich, N.H.; Vaux, W.G.; Newby, R.A.; Keairns, D.L. “Experimental/engineering support for EPA’s FBC program: Final report, Volume I. Sulfur oxide control." EPA Report, EPA-600/7-80-015a.

13. Werther, J.; Xi, W. “Jet attrition of catalyst particles in gas fluidized beds.” Powder Technol. 76 (1993) 39-46.

14. Bemrose, C.R.; Bridgwater, J.; “A review of attrition and attrition test methods.” Powder Technol. 49 (1987) 97-126.

15. Werther, J.; Reppenhagen, J. "Attrition in fluidized beds and pneumatic conveying lines." In: Fluidization, solids handling and processing, William Andrew Publishing, 1999.

16. Lupiáñez, C.; Scala, F.; Salatino, P.; Romeo, L. M.; Díez, L. I. "Primary fragmentation of limestone under oxy-firing conditions in a bubbling fluidized bed." Fuel Process. Technol. 92 (2011) 1449-1456.

17. Ayazi Shamlou, P., Z. Liu, and J. G. Yates, "Hydrodynamic influences on particle breakage in fluidized beds." Chem. Eng. Sci. 45 (1990) 809-817.

18. Vaux, W.G.; Keairns, D.L. “Particle attrition in fluid-bed processes.” In: Fluidization, Grace, J.R. and Matsen, J.M., Eds.

19. Hyang, Z.; Yi, L.; Jiang, T. "Mechanisms of strength decrease in the initial reduction of iron ore oxide pellets." Powder Technol. 221 (2012) 284-291. 
20. Rumph, H. "Physical aspects of comminution and new formulations of a law of comminution." Powder Technol. 7 (1973) 145-159.

21. Ghadiri, M.; Zhang, Z. “Impact attrition of particulate solids. Part I: A theoretical model of chipping.” Chem. Eng. Sci. 57 (2002) 3659 $-3669$.

22. Werther, J.; Reppenhagen, J. “Catalyst attrition in fludized-bed systems.” AIChE J. 45 (1999) 2001-2010.

23. Kalman, H. “Attrition control by pneumatic conveying." Powder Technol. 104 (1999) 214-220.

24. "Fluidized bed combustion," In: Steam: Its generation and use, Kitto, J.B., Stultz, S.C., Eds. 2005.

25. Xia, Y.; Cheng,L; Huang, R.; Xu, L.; Wang, Q.; Luo, Z. “Anti-wear beam effects on water wall wear in a CFB boiler.” Fuel 181 (2016) 1179-1183.

26. Xia, Y.; Cheng, L.; Yu, C.; Xu, L.; Wang, Q.; Fang, M. "Anti-wear beam effects on gas-solid hydrodynamics in a circulating fluidized bed." Particuology 19 (2015) 173-184.

27. F.A. Zenz, “Help from project E-A-R-L”. Hydrocarbon Process. 53 (1974) 119.

28. Ogawa, A. "Mechanical separation process and flow patterns of cyclone dust collectors." ASME Appl. Mech. Rev. 50 (1997) 97-130.

29. Werther, J.; Hartge, E.-U. "A population balance model of the particle inventory in a fluidized-bed reactor/regenerator system." Powder Technol. 148 (2004) 113-122.

30. Ray, Y.-C.; Jiang, T.-S.; Wen, C.Y. “Particle attrition phenomena in a fluidized bed.” Powder Technol. 49 (1987) $193-206$.

31. Holdrich, R.G. "Crushing and classification." In: Fundamentals of Particle Technology, Midland Information Technology and Publishing, 2002.

32. Tabor, D. The hardness of metals, 1951. 
33. Callister, W. D. Material science and engineering: An introduction, John Wiley and Sons, 1990.

34. Ludema, K.C. Friction, wear, lubrication: a textbook in tribology. CRC Press, 1996.

35. Biscans, B. "Impact attrition in crystallization processes. Analysis of repeated impacts events of individual crystals." Powder Technol. 143 (2004) 264- 272.

36. Archard, J.F. “Wear theory and mechanisms.” In: Wear control handbook, Peterson, M.B.; Winer, W.O., Eds. American Society of Mechanical Engineers Press, 1980.

37. Kimura, Y.; Hidaka, H.; Takaki, S. “Work-hardening mechanism during super-heavy plastic deformation in mechanically milled iron powder." Materials Trans. JIM, (1999) 40, 1149-1157.

38. Ghadiri, M.; Yuregir, K.R.; Pollock, H.M.; Ross, J.D.J.; Rolfe, N. "Influence of processing conditions on attrition of NaCl crystals." Powder Technol. 65 (1991) 311-320.

39. Mikako Takeda, Takashi Onishi, Shouhei Nakakubo and Shinji Fujimoto. "Physical properties of iron-oxide scales on Si-containing steels at high temperature." Mat. Trans. 50 (2009) 2242-2246.

40. Bartholomew, C.H. “Mechanisms of catalyst deactivation.” Applied Catalysis A: General 212 (2001) 17-60.

41. Broek, D. Elementary engineering fracture mechanics. Martinus Nijhoff Publishers, Hingham, MA, 1982.

42. Hidaka, Y.; Anraku, T.; Otsuka, N. “Tensile deformation of iron oxides at 600-1250².” Oxidation of Metals 58 (2002) $469-485$.

43. Rocha-Rangel, E. “Fracture toughness determinations by means of indentation fracture.” In: Nanocomposites with unique properties and applications in medicine and industry, Cuppoletti, J., Ed. 2011. 
44. Viktorova, S. D.; Golovinb, Yu. I.; Kochanova, A. N.; Tyurinb, A. I.; Shuklinovb, A. V.; Shuvarinb, I. A.; Pirozhkovab, T. S. “Micro- and nano-indentation approach to strength and deformation characteristics of minerals." J. Mining Sci., 50 (2014) 652-659.

45. Meng, H.C.; Ludema, K.C. “Wear models and predictive equations: Their form and content.” Wear 181-183 (1995) $443-457$.

46. Archard, J.F. “Contact and rubbing of flat surfaces.” J. Appl. Phys. 24 (1953) 981-988.

47. Yang, L.J. Wear 259 (2005) 1453-1461.

48. Ecevit, B.; Yepes, J.; Scarlett, B. “Formulation of a non-linear framework for population balance modeling of batch grinding: Beyond first-order kinetics." Chem. Eng. Sci. 61 (2006) 33 - 44.

49. Ning, Z.; Ghadiri, M. "Distinct element analysis of attrition of granular solids under shear deformation." Chem. Eng. Sci. 61 (2006) $5991-6001$.

50. Gahn, C. “Die Festigkeit von Kristallen und ihr Einfluß auf die Kinetik in Suspensionskristallisatoren." Dissertation, Technical University Munich, 1997.

51. Meier, M.; John, E.; Wieckhusen, D.; Wirth, W.; Peukert, W. "Influence of mechanical properties on impact fracture: Prediction of the milling behaviour of pharmaceutical powders by nanoindentation." Powder Technol. 188 (2009) 301-313.

52. Vogel, L.; Peukert, W. "Breakage behaviour of different materials—construction of a mastercurve for the breakage probability." Powder Technol. 129 (2003) 101- 110.

53. Zbib, M.B.; Niranjan, D.P.; Chen, W.W.; Bahr, D.F. "New pulverization parameter derived from indentation and dynamic compression of brittle microspheres." Powder Technol. 283 (2015) 57-65.

54. Ray, Y.-C.; Jiang, T.-S.; Wen, C.Y. “Particle attrition phenomena in a fluidized bed.” Powder Technol. 49 (1987) $193-206$. 
55. Paramanathan, B. K.; Bridgwater, J. “Attrition of solids-II: Material behaviour and kinetics of attrition.” Chem. Eng. Sci. 38 (1983) 207-224.

56. Gwyn, J.E. “On the particle size distribution function and the attrition of cracking catalyst.” AIChE J. (1969) 15, 35-39.

57. Neil, A. U.; Bridgwater, J. “Attrition of particulate solids under shear.” Powder Technol., 80 (1994) 207-219.

58. Neil, A. U.; Bridgwater, J. “Towards a parameter characterising attrition.” Powder Technol., 106 (1999) 37-44.

59. Bridgwater, J. “Attrition of high-density polyethylenes." Powder Technol. 50 (1987) 243-252.

60. Ghadiri, M.; Ning, Z.; Kenter, S.J.; Puik, E. “Attrition of granular solids in a shear cell.” Chem Eng Sci 55 (2000) 5445.

61. Ayazi Shamlou, P., Liu, Z.; Yates, J.G. “Hydrodynamic influences on particle breakage in fluidized beds.” Chem. Eng. Sci., 45 (1990) 809-817.

62. Blinichev, V.N.; Strel'tsov, V.V.; Lebedeva, E.S. “An investigation of the size reduction of granular materials during their processing in fluidized beds." Intl. Chem. Eng. 8 (1968) 615-618.

63. Lim, E.W.C.; Wang, C.-H. “Diffusion modeling of bulk granular attrition.” Ind. Eng. Chem. Res. (2006) 45, 2077-2083.

64. Paramanathan, B.K.; Bridgwater, J. “Attrition of solids - 1. Cell development.” Chem. Eng. Sci. 38 (1983) 197-206.

65. Stein, M.; Seville, J.P.K.; Parker, D.J. “Attrition of porous glass particles in a fluidized bed.” Powder Technol. 100 (1998) $242-250$.

66. Ghadiri, M.; Cleaver, J.A.S.; Tuponogov, V.G.; Werther, J. "Attrition of FCC powder in the jetting region of a fluidized bed." Powder Technol. 80 (1994) 175-178.

67. Tamjid, S.; Hashemabadi, S.H.; Shirvani, M. “Prediction of catalyst attrition in a regeneration cyclone.” Filtr. Sep. 47 (2010) $29-33$. 
68. Han, T.; Levy, A.; Kalman, H. "DEM simulation for attrition of salt during dilute-phase pneumatic conveying." Powder Technol. 129 (2003) 92-100.

69. Lim, E. W. C.; Wang, C.-H. “Granular Attrition as a Diffusion Phenomenon.” AIChE Annual Meeting Cincinnati, Ohio, October 30 November 4, 2005, 209f.

70. Zhang, Z. “Impact attrition of particulate solids.” Ph.D. thesis. University of Surrey, UK. 1994.

71. Thornton, C.; Ning, Z. "A theoretical model for the stick/bounce behaviour of adhesive, elastic-plastic spheres." Powder Technol. 99 (1998) 154-162.

72. Chen, Z.; Lim C. J.; Grace J. R. “Study of limestone particle impact attrition.” Chem. Eng. Sci. 62 (2007) 867 - 877.

73. vanLaarhoven, B.; Schaafsma, S.H.; Meesters, G.M.H. "Toward a desktop attrition tester; validation with dilute phase pneumatic conveying." Chem. Eng. Sci. 73 (2012) 321-328.

74. Lecoq, O., Chouteau, N., Mebtoul, M., Large, J.-F, Guigon, P. "Fragmentation by high velocity impact on a target: a material grindability test." Powder Technol. 133 (2003) 113- 124.

75. Zhang, B., Zhao, Y., Duan, C., Tang, L., Dong, L., Qu, J. “Magnetite particle surface attrition model in dense phase gas-solid fluidized bed for dry coal beneficiation." Advanced Powder Technol. 25 (2014) 1031-1037.

76. Pougatch, K.; Salcudean, M.; McMillan, J. “Simulation of particle attrition by supersonic gas jets in fluidized beds.” Chem. Eng. Sci. 65 (2010) 4829-4843.

77. Wang, Q.; Luo, Z.; Ni, M.; Cen, K. "Particle population balance model for a circulating fluidized bed boiler." Chem. Eng. J. 93 (2003) $121-133$. 
78. Kramp, M.; Thon, A.; Hartge, E.-U.; Heinrich, S.; Werther, J. "The role of attrition and solids recovery in a chemical looping combustion process." Oil Gas Sci. Tech-Rev. IFP Energ. Nov. 66 (2011) 277-290.

79. Bilgili, E.; Yepes, J.; Scarlett, B. “Formulation of a non-linear framework for population balance modeling of batch grinding: Beyond first-order kinetics." Chem. Eng. Sci. 61 (2006) 33-44.

80. Ouchiyama, N.; Rough, S.L.; Bridgwater, J. “A population balance approach to describing bulk attrition.” Chem. Eng. Sci. 60 (2005) 1429-1440.

81. Hartge, E.-U.; Klett, C.; Werther, J. "Dynamic simulation of the particle size distribution in a circulating fluidized bed combustor." Chem. Eng. Sci. 62 (2007) 281-293.

82. Redemann, K.; Hartge, E.-U.; Werther, J. “A particle population balancing model for a circulating fluidized bed combustion system.” Powder Technol. 191 (2009) 78-90.

83. Capece, M.; Bilgili, E.; Dave, R. "Insight into first-order breakage kinetics using a particle-scale breakage rate constant." Chem. Eng. Sci. 117 (2014) 318-330.

84. Xu, W.; DeCroix, D.S.; Sun, X. “Mechanistic based DEM simulation of particle attrition in a jet cup.” Powder Technol. 253 (2014) 385392.

85. Yuregir, K. R.; Ghadiri, M.; Clift, R. “Observation of impact attrition of granular solids.” Powder Technol. 49 (1986) 53-57.

86. Elmustafa, A.A.; Stone, D.S. "Nanoindentation and the indentation size effect: Kinetics of deformation and strain gradient plasticity." J. Mech. Phys. Solids 51 (2003) 357 - 381. 
87. Oliver, W.C.; Pharr, G.M. “An improved technique for determining hardness and elastic modulus.” J. Mater. Res. 7 (1992) 1564 1583.

88. Hay, J. "The revolutionary impact of the Oliver and Pharr technique on the science of hardness testing - application note." Technical note, Agilent Technologies, 2013.

89. Morris, D.; Vodnick. A.M.; Cook, R.F. "Radial fracture during indentation by acute probes: II, Experimental observations of cubecorner and Vickers indentation." Int. J. Fracture 136 (2005) 265-284.

90. Doerner, M.F.; Nix, W.D. “A method for interpreting the data from depth-sensing indentation instruments." J. Mater. Res. 1 (1986) 601-609.

91. Taylor, L.J.; Papadopoulos, D.G.; Dunn, P.J.; Bentham, A.C.; Mitchell, J.C.; Snowden, M.J. "Mechanical characterisation of powders using nanoindentation." Powder Tech. 143-144 (2004) 179- 185.

92. Couroyer, C.; Ghadiri, M.; Laval, P.; Brunard, N.; Kolenda. F. “Methodology for investigating the mechanical strength of reforming catalyst beads." Oil Gas Sci. Tech. - Rev. IFP 55 (2000) 67-85.

93. Trenkle, J.C.; Packard, C.E.; Schuh, C.A. “Hot nanoindentation in inert environments.” Rev. Sci. Instr. 81 (2010) 073901.

94. Arteaga, P.A.; Ghadiri, M.; Lawson, N.S. Pollock, H.M. "Use of nanoindentation to assess potential attrition of particulate solids." Tribology Intl. 26 (1993) 305-310.

95. Thon, A.; Kramp, M.; Hartge, E.-U.; Heinrich, S.; Werther, J. "Catalyst Attrition in the CFB Riser." In: 10th International Conference on Circulating Fluidized Beds and Fluidization Technology - CFB-10, T. Knowlton, PSRI, Eds., ECI Symposium Series, Volume RP7, 2013. 96. Thon, A.; Werther, J. “Attrition resistance of a VPO catalyst.” Appl. Cat. A: Gen. 376 (2010) 56-65. 
97. Forsythe, W. L.; Hertwig, W. R. “Attrition characteristics of fluid cracking catalysts.” Ind. Eng. Chem. 41 (1949) 1200 - 1206.

98. Wu, D.; Gu, Z.; Li, Y. “Attrition of catalyst particles in a laboratory-scale fluidized-bed reactor.” Chem. Eng. Sci. 135 (2015) 431-440.

99. Mullier, M.A.; Seville, J.P.K.; Adams, M.J. “The effect of agglomerate strength on attrition during processing.” Powder Technol., 65 (1991) 321-333.

100. Yao, X.; Zhang, H.; Yang, H.; Liu, Q.; Wang, J.; Yue, G. “An experimental study on the primary fragmentation and attrition of limestones in a fluidized bed." Fuel Process. Technol. 91 (2010) 1119-1124.

101. Brown, T.A.; Scala, F.; Scott, S.A.; Dennis, J.S.; Salatino, P. “The attrition behavior of oxygen-carriers under inert and reacting conditions." Chem. Eng. Sci. 71 (2012) 449-467.

102. Wu, D.; Wu, F.; Gu, Z. “Catalyst attrition in an ASTM fluidized bed.” Catalysis Today 264 (2016) 70-74.

103. Kono, H. "Attrition rates of relatively coarse solid particles in various types of fluidized beds." AIChE Symposium Series 205 (1981) 96-106.

104. Zhang, Z.; Ghadiri, M. “Impact attrition of particulate solids. Part 2: Experimental work.” Chem. Eng. Sci. 57 (2002) 3671 3686.

105. Chen, Z.; Lim, C.J.; Grace, J.R. “Study of limestone particle impact attrition.” Chem. Eng. Sci. 62 (2007) 867 - 877.

106. Amblard, B.; Bertholin, S.; Bobin, C.; Gauthier, T. "Development of an attrition evaluation method using a jet cup rig." Powder Technol. 274 (2015) 455-465.

107. Cocco, R.; Arrington, Y.; Hays, R.; Findlay, J.; Karri, S.B.R.; Knowlton, T.M. “Jet cup attrition testing.” Powder Technol. 200 (2010) 224-233. 

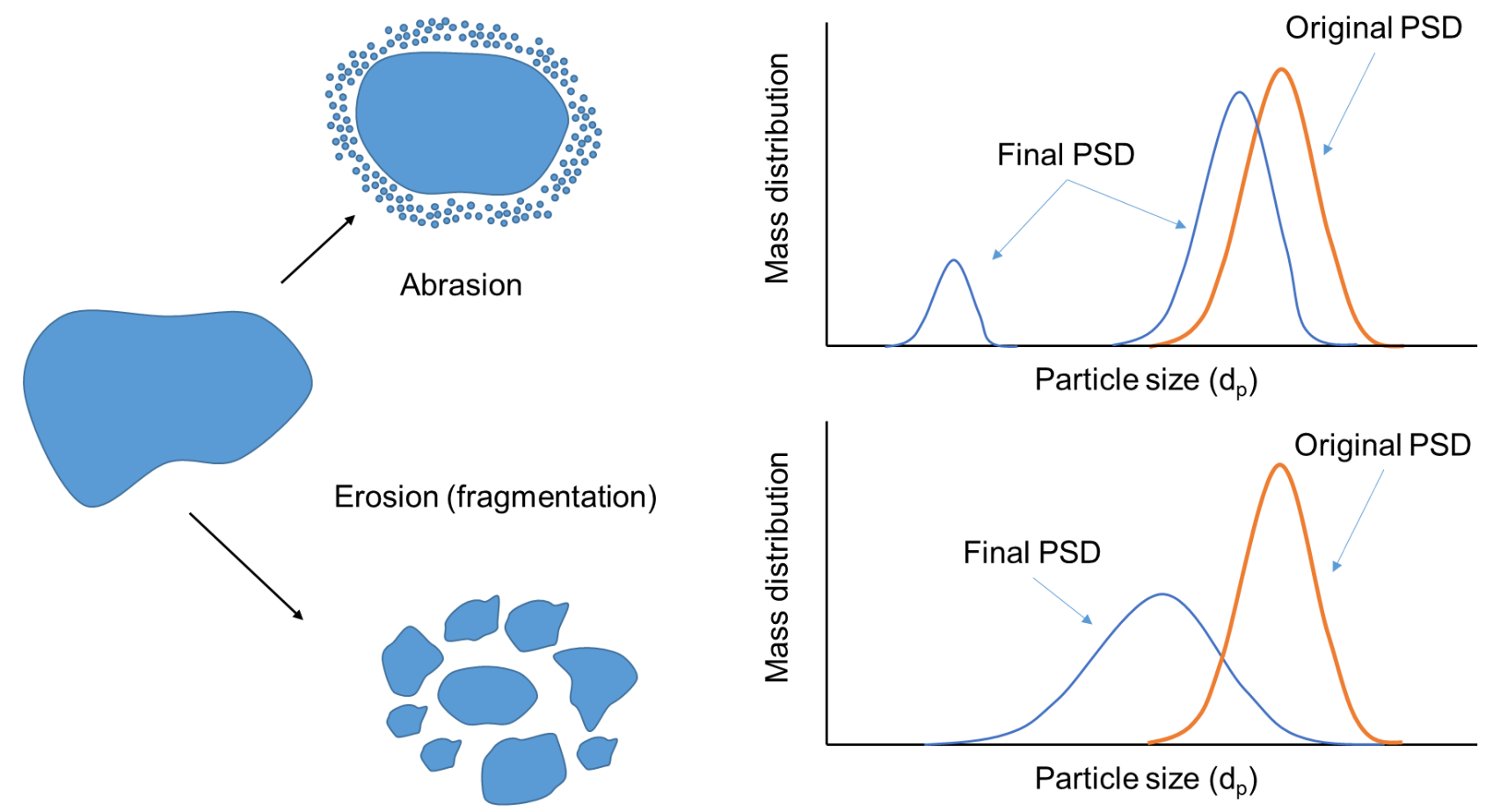

Figure 1. Particle size distributions of abrasion and erosion attrition mechanisms [15]. 


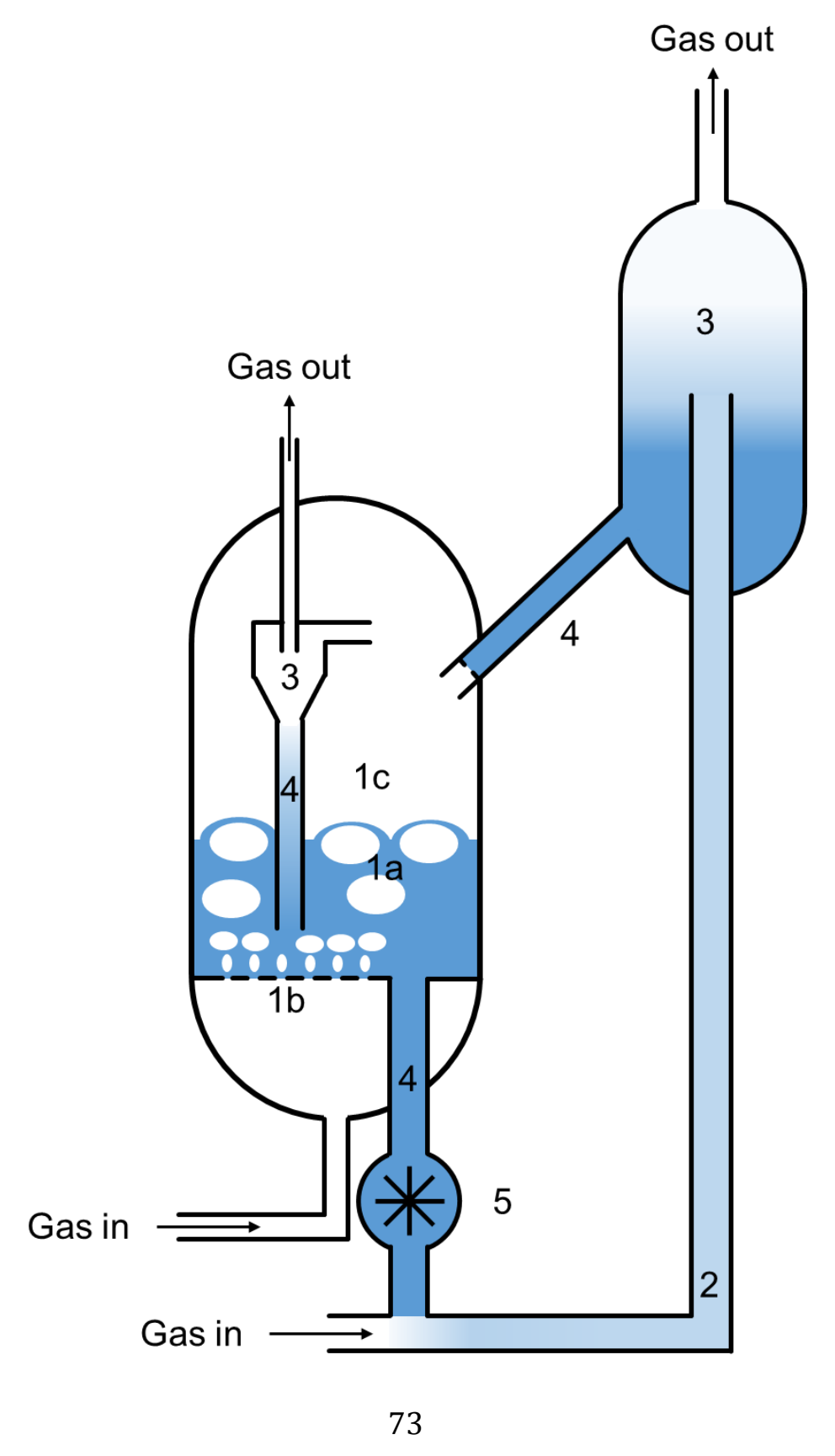


Figure 2. Locations of attrition in a circulating fluidized bed (CFB) system. Modified from [7].

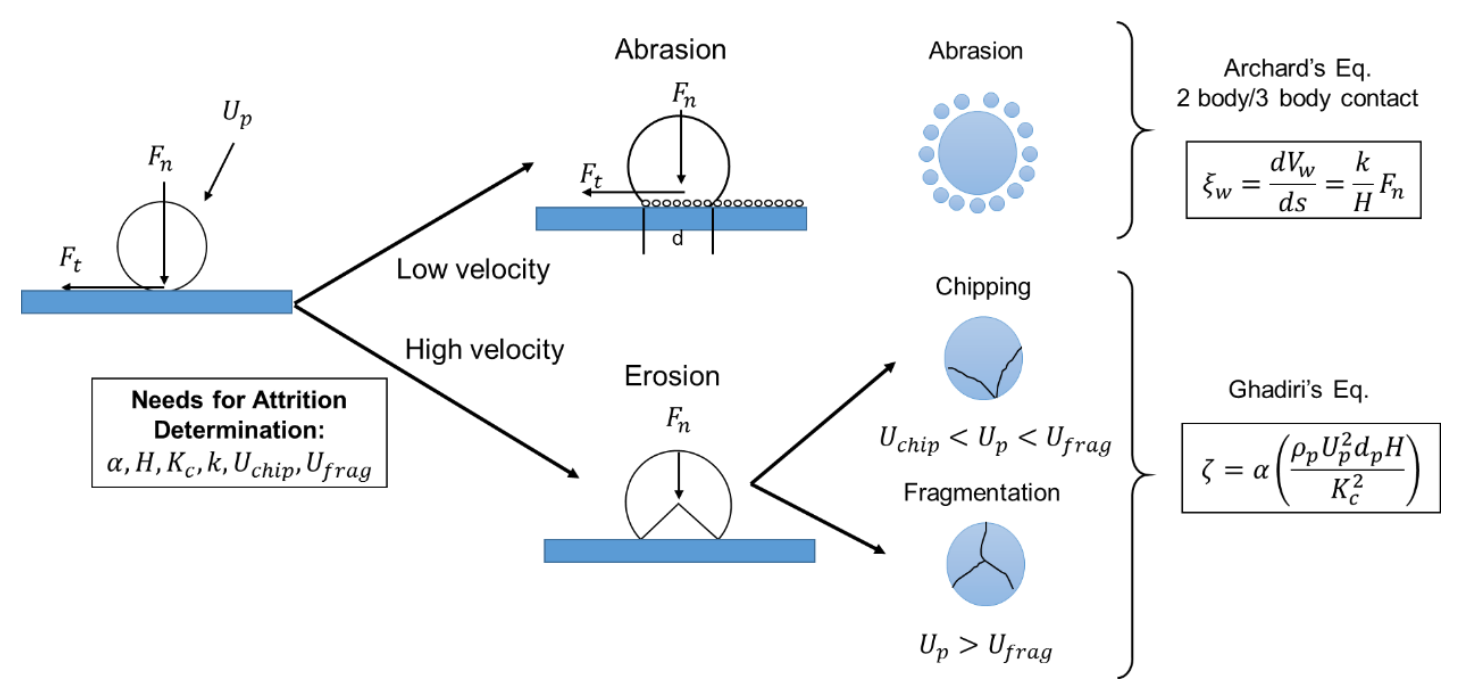

Figure 3. Summary of abrasion and erosion expressions. 


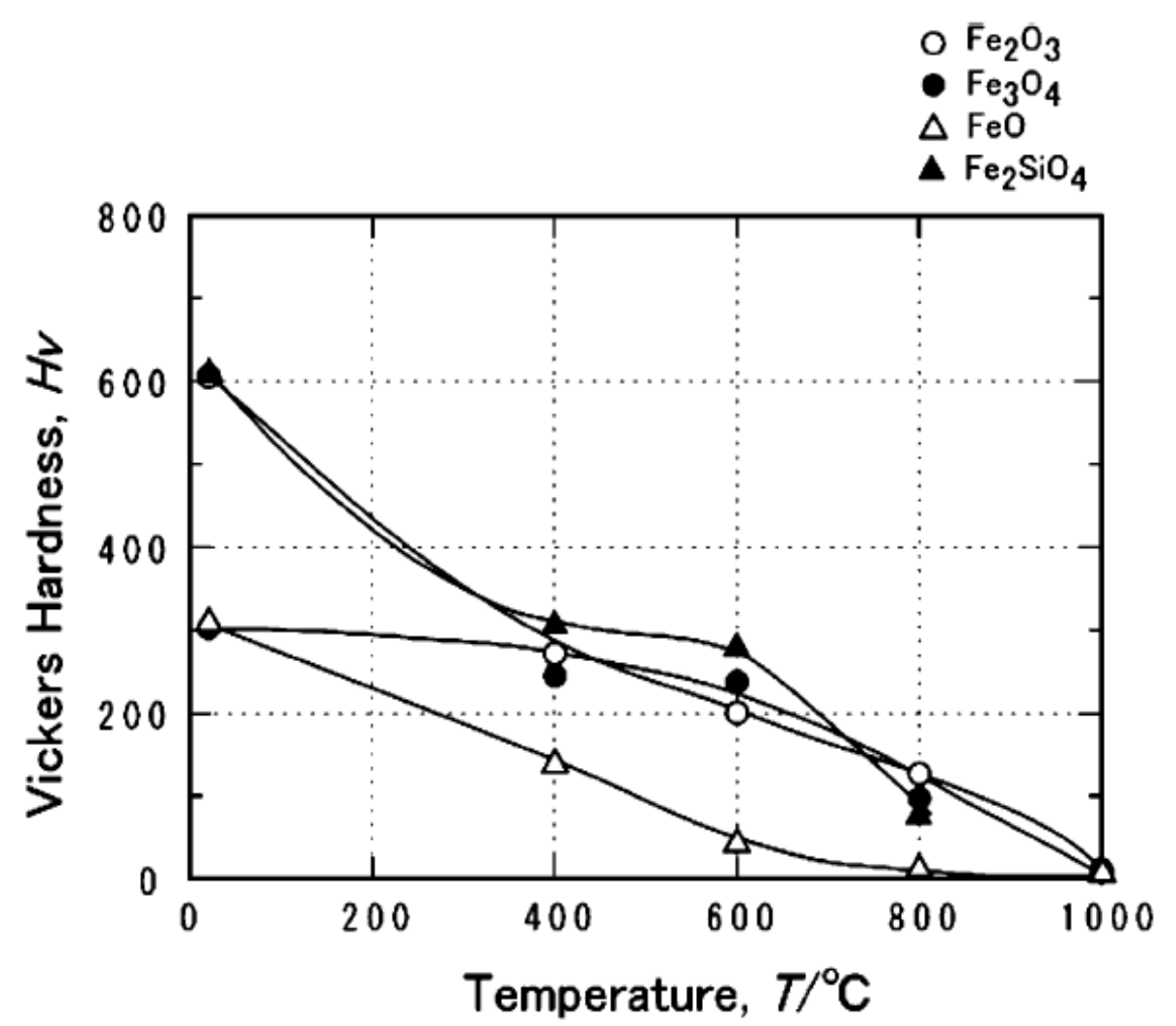

Figure 4. Hardness of iron oxides and an iron silicate as a function of temperature [39]. 


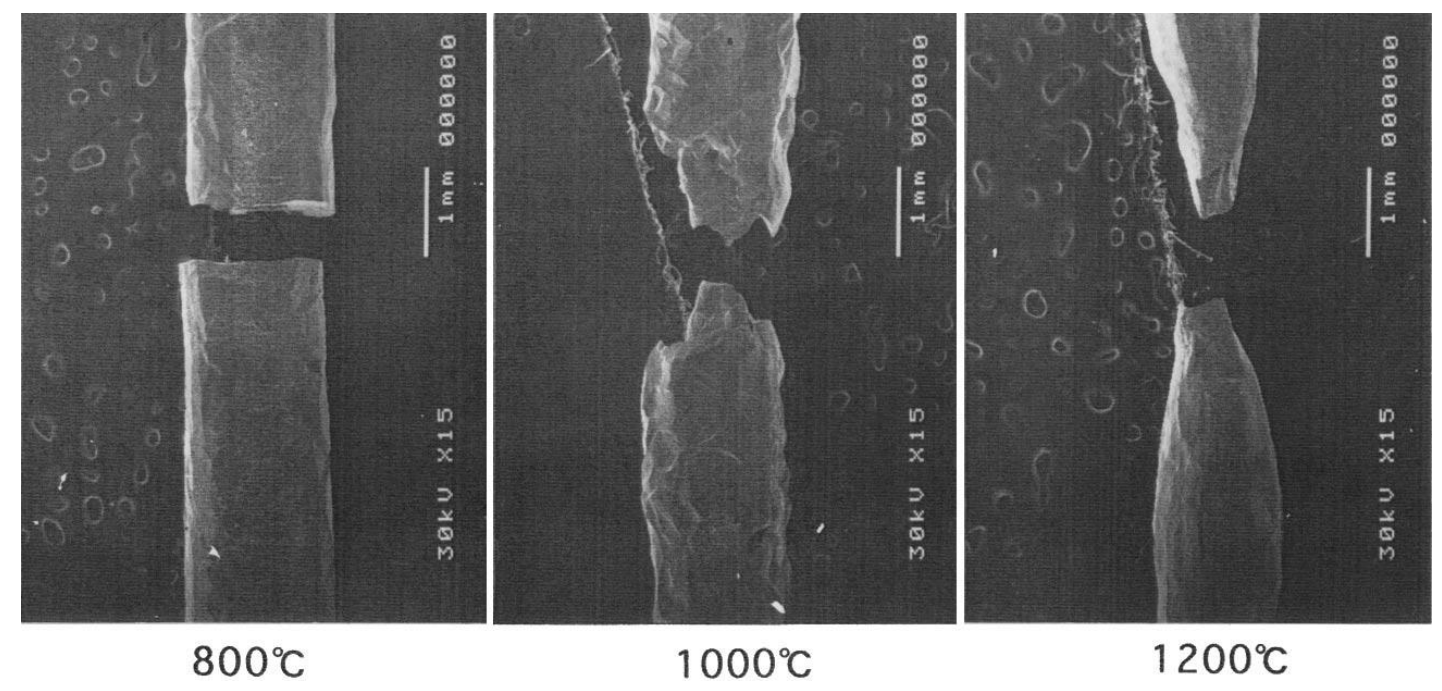

Figure 5. Fracture properties of alpha-iron oxide from tensile stress testing [42].

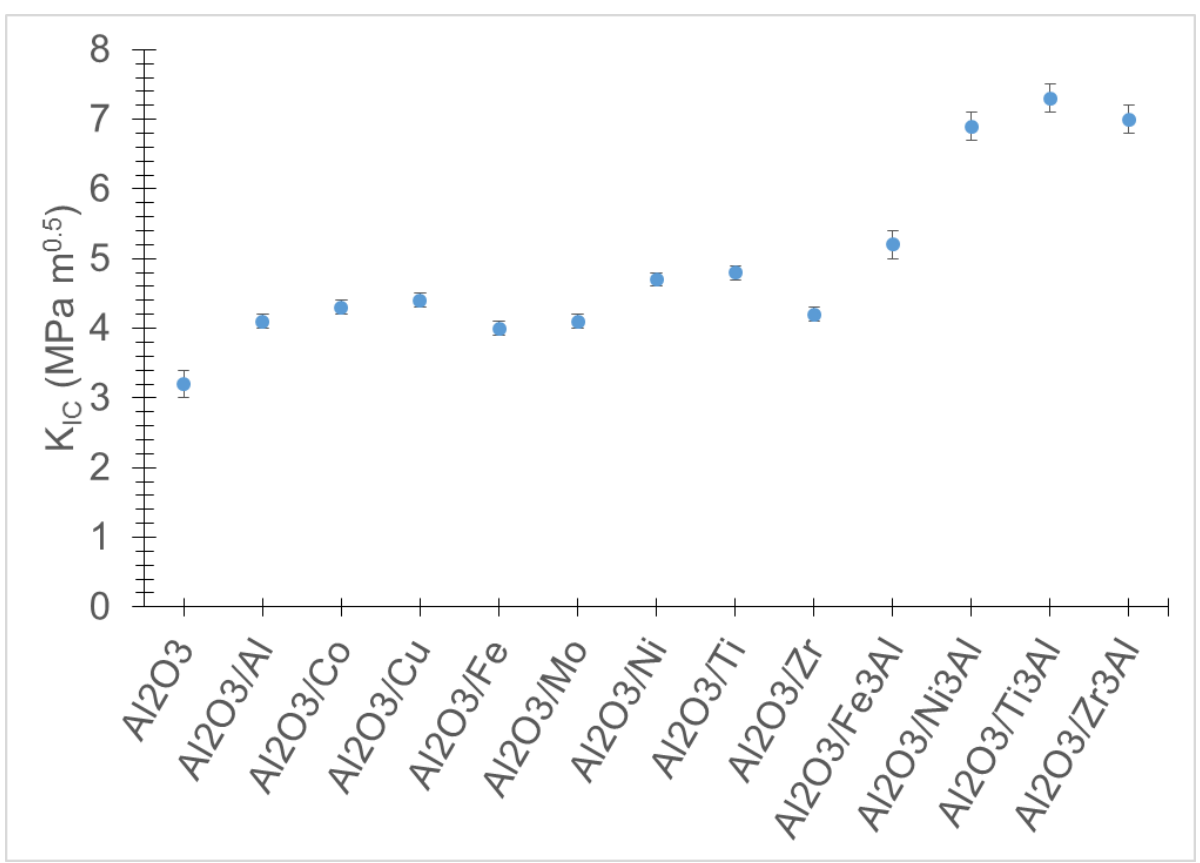


Figure 6. Fracture toughness of various metallic and oxide composites of alumina [43].
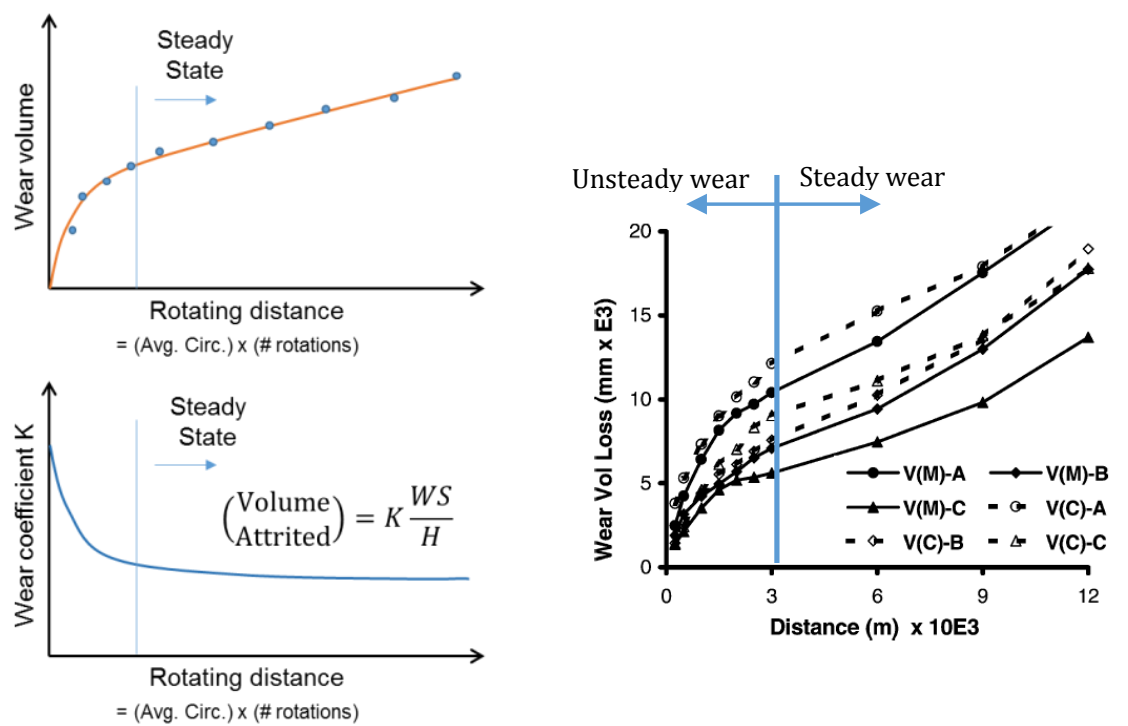

Figure 7. a.) Unsteady and steady wear as a function of sliding distance. b.) Wear volume for aluminum samples [47]. 
(a)

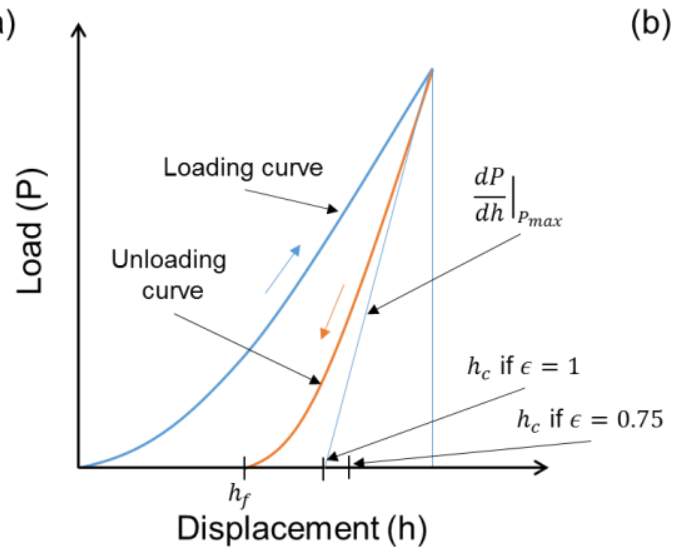

(b)

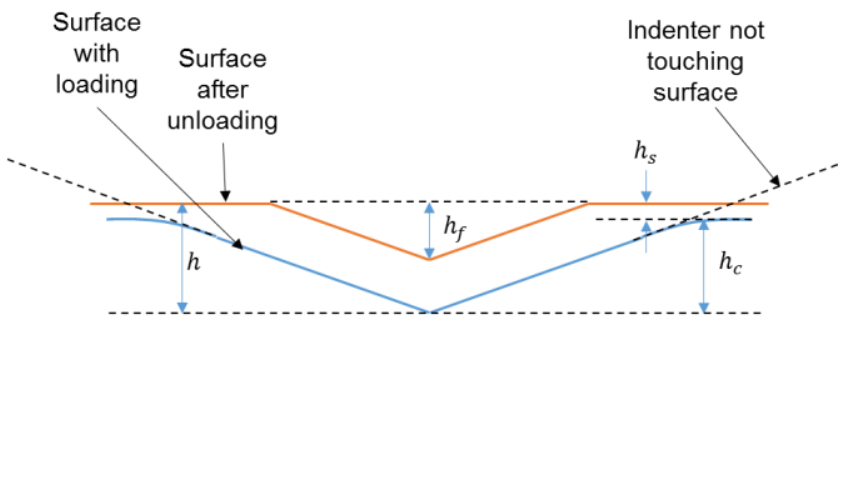

Figure 8. (a) Representative nanoindentation loading and unloading curve. (b) Side view of indentation process, showing the elastic and plastic portions around the area of indentation. Both modified from [87].

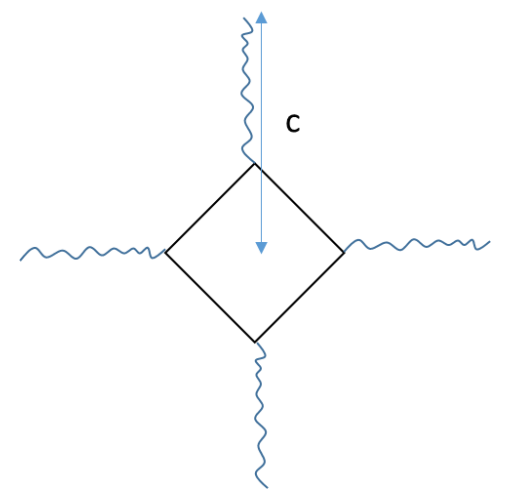

Figure 9. Crack length after indentation. 


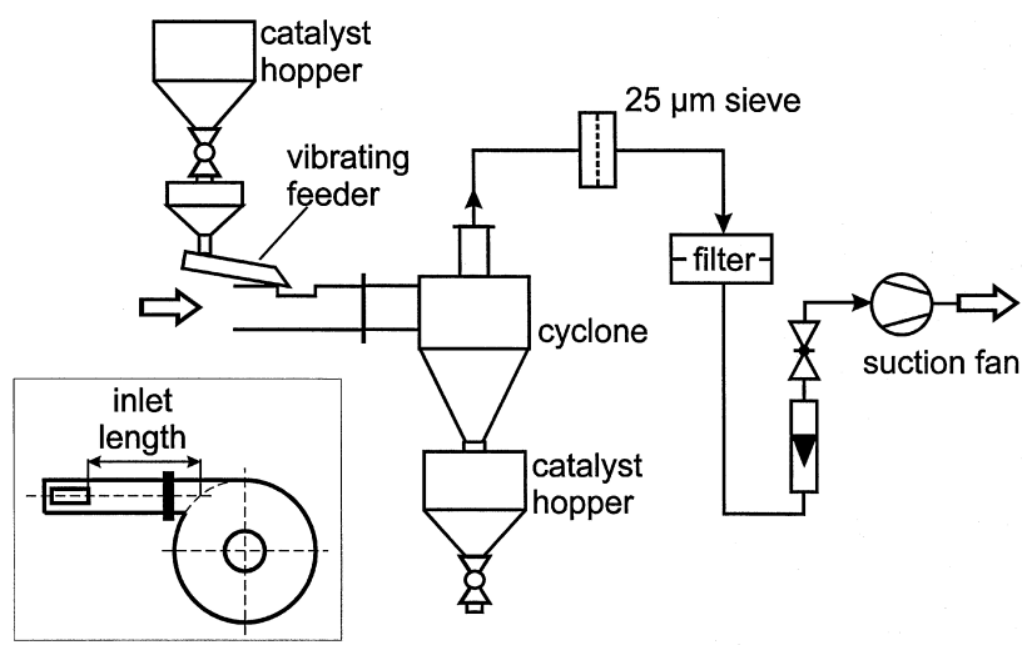

Figure 10. Experimental setup for cyclone attrition experiments [11] 


\section{Annular Shear Cell}

Force applied

over measured

rotational strain

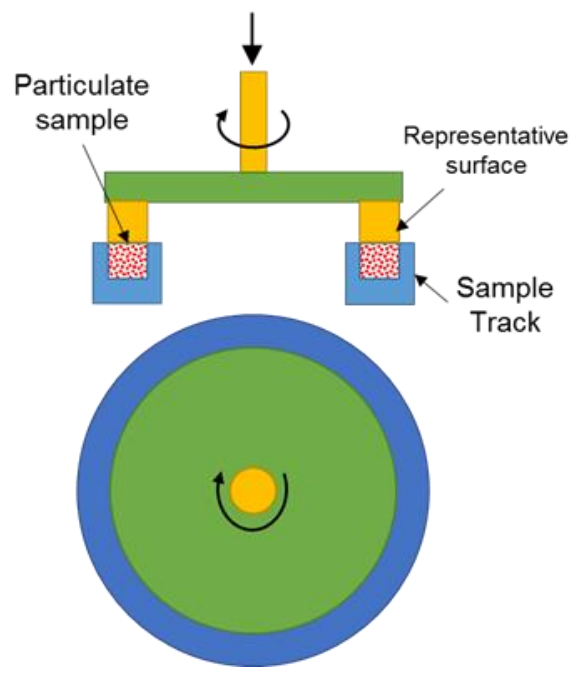

Figure 11. Annular shear cell experimental setup. Modified from [55]. 


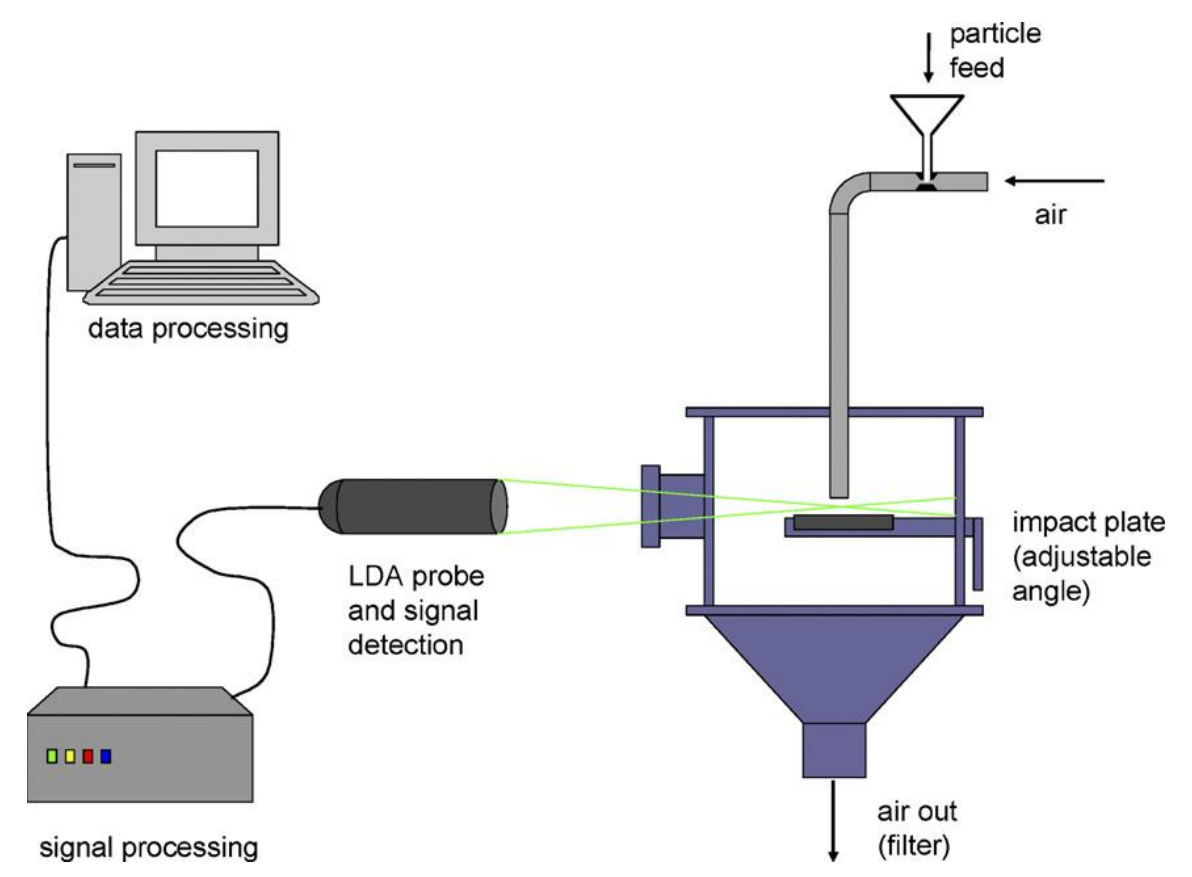

Figure 12. Impact attrition device [51].

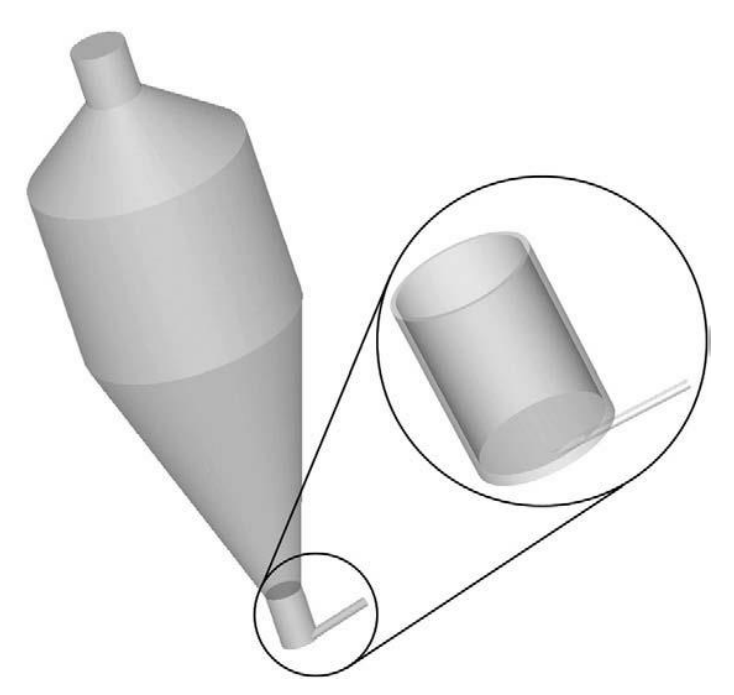


Figure 13. Grace-Davidson jet cup attrition device [107].

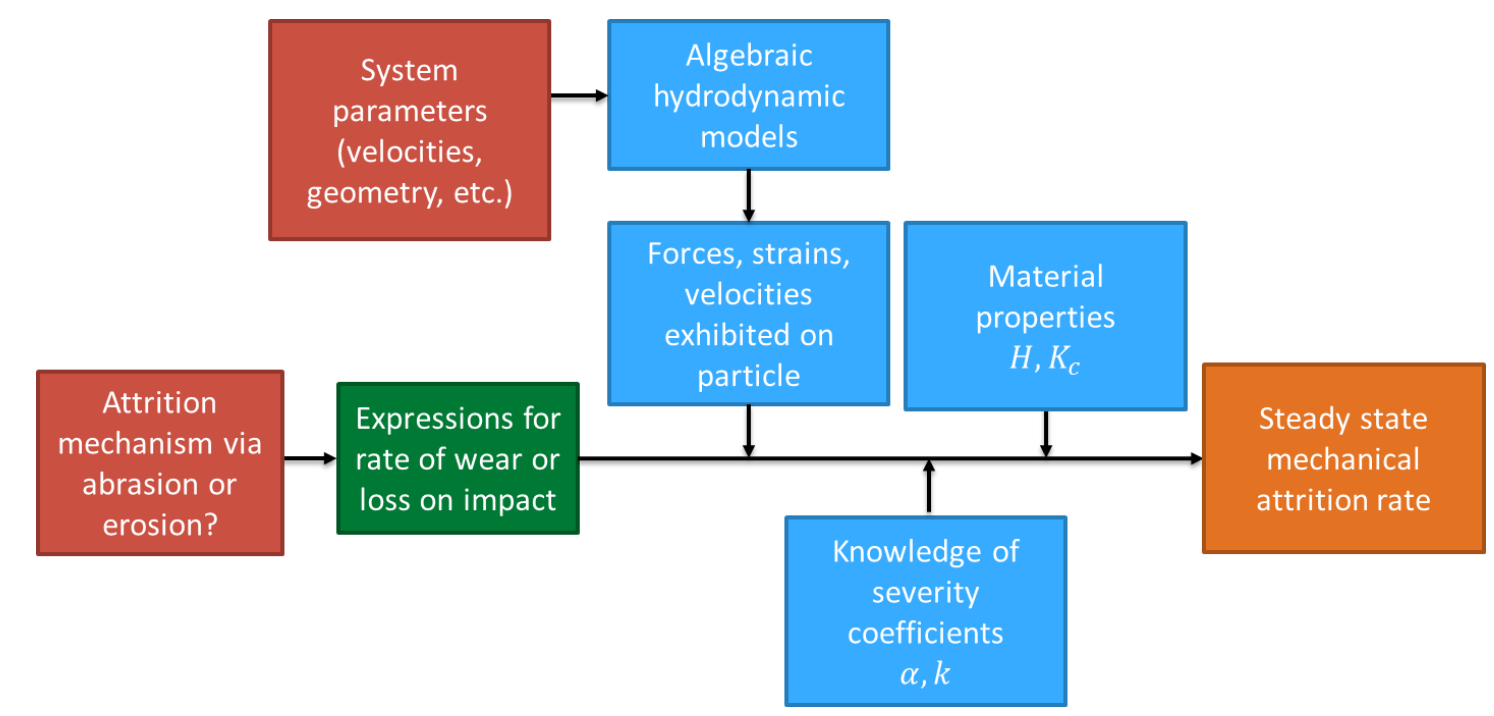

Figure 14. Algebraic modeling approach to attrition based on fundamental material properties.Table 1. Nanoindentation of particulate solids.

\begin{tabular}{|c|c|c|c|c|}
\hline Material & $\begin{array}{l}\text { Hardness } \\
\text { (GPa) }\end{array}$ & $\frac{\frac{\text { Elastic }}{\text { modulus }}}{\text { (GPa) }}$ & $\begin{array}{l}\text { Fracture } \\
\text { Toughness } \\
\left.\text { (MPa m }{ }^{0.5}\right)\end{array}$ & $\frac{\frac{\text { Particle }}{\text { diameter }}}{(\mu \mathrm{m})}$ \\
\hline Soda lime glass [53] & 6.5 & 83.0 & 1.3 & 1285 \\
\hline Silica [53] & 13.8 & 111.0 & 1.1 & 691 \\
\hline Silicon [53] & 9.7 & 164.0 & 0.6 & 966 \\
\hline Barium titanate glass [53] & 5.3 & 77.0 & 1.1 & 923 \\
\hline Yttrium stabilized zirconia [53] & 16.0 & 255.0 & 5.7 & 822 \\
\hline Alumina reforming beads [92] & 0.3 & 10.0 & 0.2 & $1700-2000$ \\
\hline Sildenafil citrate [91] & 0.5 & 13.9 & 0.019 & 402 \\
\hline Voriconazole [91] & 0.1 & 3.7 & $\mathrm{n} / \mathrm{a}$ & 250 \\
\hline
\end{tabular}


Table 2. Attrition studies of catalysts in cyclones.

\begin{tabular}{|l|l|l|l|l|}
\hline & Catalyst & Inlet gas velocity & $\begin{array}{l}\text { Solids loading }(\boldsymbol{\mu}) \\
(\mathbf{k g} / \mathbf{k g})\end{array}$ & $\begin{array}{l}\text { Attrition Rate } \\
\mathbf{( k g / k g )}\end{array}$ \\
\hline $\begin{array}{l}\text { Thon and Werther } \\
{[96]}\end{array}$ & $\begin{array}{l}\text { Vanadium } \\
\text { phosphorus oxide } \\
\text { FCC catalyst, used } \\
\text { and fresh }\end{array}$ & $15-25 \mathrm{~m} / \mathrm{s}$ & $0.5-2.0$ & $\begin{array}{l}\text { Used: } \\
6-93 \times 10^{-6} \\
\text { Fresh: } \\
52-271 \times 10^{-6}\end{array}$ \\
\hline $\begin{array}{l}\text { Reppenhagen and } \\
\text { Werther [11] }\end{array}$ & $\begin{array}{l}\text { FCC catalyst, used } \\
\text { and fresh }\end{array}$ & $8-24 \mathrm{~m} / \mathrm{s}$ & $0.05-1$ & $\begin{array}{l}\text { Used: } \\
3-270 \times 10^{-6} \\
\text { Fresh: } \\
35-370 \times 10^{-6}\end{array}$ \\
\hline
\end{tabular}

Table 3. Fluidized bed attrition studies.

\begin{tabular}{|c|c|c|c|c|c|c|}
\hline Author(s) & Vessel Size & Gas Velocity & Temp. & Bed Material and Size & $\begin{array}{l}\text { Attrition Rate } \\
\text { Measured }\left(\mathbf{s}^{-1}\right) *\end{array}$ & Remarks \\
\hline Ray et al. [30] & $\begin{array}{l}\mathrm{D}=0.1 \mathrm{~m} \\
\mathrm{H}=1.2 \mathrm{~m}\end{array}$ & $\begin{array}{l}U-U_{m f} \\
=0.5 \\
-1.7 \mathrm{~m} / \mathrm{s}\end{array}$ & $\begin{array}{l}\text { Room } \\
\text { temp }\end{array}$ & $\begin{array}{l}\text { Limestone, } 300-1000 \\
\mu m\end{array}$ & $3.2-6.3 \times 10^{-8}$ & $\begin{array}{l}\text { Porous plate } \\
\text { distributor. }\end{array}$ \\
\hline $\begin{array}{l}\text { Ulrich et al. } \\
{[12] .}\end{array}$ & $\mathrm{D}=0.035 \mathrm{~m}$ & $U_{g}=1.2 U_{m f}$ & $\begin{array}{l}815^{\circ} \mathrm{C}, \\
\text { heated at } \\
10^{\circ} \mathrm{C} / \mathrm{min}\end{array}$ & $\begin{array}{l}\text { Limestone, } \\
1000-1400 \mu m\end{array}$ & $\begin{array}{l}1-2.2 \times 10^{-4}(\mathrm{C}) \\
\mathrm{S} 5.6 \times 10^{-5}(\mathrm{~S})\end{array}$ & $\begin{array}{l}\text { Attrition based } \\
\text { on } d_{p}<710 \mu m\end{array}$ \\
\hline $\begin{array}{l}\text { Wu et al. } \\
{[102]}\end{array}$ & $\begin{array}{l}34 \mathrm{~mm} \phi, 710 \mathrm{~mm} \\
\text { high ASTM bed }\end{array}$ & $\begin{array}{l}U_{g}=0.0834- \\
0.1951 \mathrm{~m} / \mathrm{s}\end{array}$ & $\begin{array}{l}\text { Room } \\
\text { temp }\end{array}$ & FCC catalyst & $1-8 \times 10^{-6}$ & $\begin{array}{l}\text { Bubbling } \\
\text { attrition } \\
\text { ascertained from } \\
\text { jetting bed } \\
\end{array}$ \\
\hline $\begin{array}{l}\text { Yao et al. } \\
{[100]}\end{array}$ & $\mathrm{D}=0.054 \mathrm{~m}$ & $U_{g}=0.5 \mathrm{~m} / \mathrm{s}$ & $850^{\circ} \mathrm{C}$ & $\begin{array}{l}\text { Lime and sulfated } \\
\text { limestone, } \\
200-400 \mathrm{um} \\
400-600 \mathrm{um}\end{array}$ & $\begin{array}{l}0.6-1.8 \times 10^{-5}(\mathrm{C}) \\
0.4-3 \times 10^{-6}(\mathrm{~S}) \\
0.03-1.1 \times 10^{-5}(\mathrm{C}) \\
0.16-1.5 \times 10^{-6}(\mathrm{~S})\end{array}$ & $\begin{array}{l}\text { Porous } \\
\text { distributor }\end{array}$ \\
\hline Kono [103] & Fluid bed: & $U_{g}=0.8-8$ & $25-504{ }^{\circ} \mathrm{C}$ & Alumina-silica, & Fluid bed: & Unknown \\
\hline
\end{tabular}




\begin{tabular}{|c|c|c|c|c|c|c|}
\hline & $\begin{array}{l}\mathrm{D}=0.105-0.380 \mathrm{~m} \\
\mathrm{H}=0.25-2 \mathrm{D} \\
\text { Spouted bed: } \\
\text { Cone angle }=40-90^{\circ}\end{array}$ & $\begin{array}{l}\mathrm{m} / \mathrm{s} \\
\bar{U}=1.5-15 \\
\mathrm{~m} / \mathrm{s}\end{array}$ & & $\begin{array}{l}\text { Various ranges } \\
\text { between } 970-5600 \mu \mathrm{m}\end{array}$ & $\begin{array}{l}0.25-3.6 \times 10^{-4} \\
\text { Spouted bed: } \\
1 \times 10^{-5}-2 \times 10^{-3}\end{array}$ & distributor \\
\hline $\begin{array}{l}\text { Zhang et al. } \\
\text { [4] }\end{array}$ & $\begin{array}{l}\mathrm{D}=0.0662,0.1 \mathrm{~m} \\
\mathrm{H}=2.5 \mathrm{~m} \\
d_{o r}=3-5 \mathrm{~mm}\end{array}$ & $\begin{array}{l}\text { Ug } \\
=1-5 U_{m f} \\
U_{o r}=12- \\
130 \mathrm{~m} / \mathrm{s}\end{array}$ & $\begin{array}{l}\text { Room } \\
\text { temp }\end{array}$ & $\begin{array}{l}\text { Silica sand: } \\
200-400 \mu \mathrm{m} \\
\text { Silicon carbide: } \\
60 \mu \mathrm{m} \\
\text { FCC: } \\
40-60 \mu \mathrm{m} \\
\text { Limestone: } \\
250-470 \mu \mathrm{m}\end{array}$ & $\begin{array}{l}\text { FCC: } \\
2.1-6.9 \times 10^{-7}(\mathrm{FB}) \\
3.5-6.9 \times 10^{-7}(\mathrm{~J}) \\
\text { Silica: } \\
0.9-2.9 \times 10^{-6}(\mathrm{FB}) \\
0.7-4.3 \times 10^{-6}(\mathrm{~J}) \\
\text { Silica (large): } \\
0.9-9 \times 10^{-7} \\
\text { SiC: } \\
2.0-7.4 \times 10^{-8}\end{array}$ & $\begin{array}{l}\text { Perforated plate } \\
\text { distributor, with } \\
\text { jet added } 5 \mathrm{~cm} \\
\text { above distributor }\end{array}$ \\
\hline $\begin{array}{l}\text { Brown et al. } \\
\text { [101] }\end{array}$ & $\begin{array}{l}D=0.04 \mathrm{~m} \\
\mathrm{H}=1 \mathrm{~m}\end{array}$ & $\begin{array}{l}0.8 \mathrm{~m} / \mathrm{s}\left(U_{m f}\right. \\
=0.09 \mathrm{~m} / \mathrm{s})\end{array}$ & $\begin{array}{l}850^{\circ} \mathrm{C}, \\
\text { cyclic } \\
\text { reduction, } \\
\text { oxidation }\end{array}$ & $\begin{array}{l}\text { Unsupported iron } \\
\text { oxide, } \\
\text { copper oxide } \\
\text { impregnated on } \\
\text { alumina, } \\
400-600 \mu \mathrm{m} \\
\end{array}$ & $\begin{array}{l}\mathrm{Fe}_{2} \mathrm{O}_{3}: \\
1.9 \times 10^{-6} \\
\mathrm{CuO} \text { on alumina: } \\
4.5 \times 10^{-7}\end{array}$ & $\begin{array}{l}\text { Perforated plate } \\
\text { distributor }\end{array}$ \\
\hline $\begin{array}{l}\text { Werther and } \\
\text { Xi [13] }\end{array}$ & $\begin{array}{l}D=0.050 \mathrm{~m} \\
d_{\text {or }}=0.5-2 \mathrm{~mm}\end{array}$ & $\begin{array}{l}U_{g}=0.2 \\
\mathrm{~m} / \mathrm{s} \\
U_{o r}=25- \\
100 \mathrm{~m} / \mathrm{s}\end{array}$ & $\begin{array}{l}\text { Room } \\
\text { temp }\end{array}$ & $\begin{array}{l}\text { Spent FCC catalyst from } \\
\text { Shell } \\
\text { Fresh catalyst from } \\
\text { Akzo }\end{array}$ & $\begin{array}{l}\text { Spent FCC: } \\
2.3 \times 10^{-7}(\mathrm{FB}) \\
5.0 \times 10^{-7}(\mathrm{~J}) \\
\text { Fresh FCC: } \\
1.9 \times 10^{-7}(\mathrm{FB}) \\
4.3 \times 10^{-7}(\mathrm{~J})\end{array}$ & $\begin{array}{l}\text { Bubble- and jet- } \\
\text { induced attrition } \\
\text { measured } \\
\text { simultaneously }\end{array}$ \\
\hline
\end{tabular}

* Condition key: (C): Calcination, (S): Sulfation, (FB): Fluidized Bed, (J) Jet 